Portland State University

PDXScholar

Summer 1-1-2012

\title{
Shaping the Future Past: Finding History, Creating Identity in the Kwan Hsu Papers
}

Lisa Chere' Donnelly

Portland State University

Follow this and additional works at: https://pdxscholar.library.pdx.edu/open_access_etds

Part of the Biological and Chemical Physics Commons, Business Commons, Chinese Studies Commons, and the Higher Education and Teaching Commons Let us know how access to this document benefits you.

\section{Recommended Citation}

Donnelly, Lisa Chere', "Shaping the Future Past: Finding History, Creating Identity in the Kwan Hsu Papers" (2012). Dissertations and Theses. Paper 481.

https://doi.org/10.15760/etd.481

This Thesis is brought to you for free and open access. It has been accepted for inclusion in Dissertations and Theses by an authorized administrator of PDXScholar. Please contact us if we can make this document more accessible: pdxscholar@pdx.edu. 
Shaping the Future Past: Finding History, Creating Identity in the Kwan Hsu Papers

by

Lisa Chere' Donnelly

A thesis in submitted in partial fulfillment of the requirements for the degree of

Master of Arts

in

History

Thesis Committee:

William Lang, Chair

Linda Walton

Cristine Paschild

Katrine Barber

Portland State University

(C)2012 
ABSTRACT

Kwan Hsu was neither a superstar nor a celebrity. Her name does not come up in conversations about important contributors to her field of biophysics nor is she instantly recognizable for her contributions to Portland State University's international program or the state of Oregon's business ties with China. Yet she was a contributor, a cog-in-the-wheel, at the very least, in all of these areas and more. She was a peripheral member of a well-known Chinese family, but few in the United States know of or perhaps have interest in, but otherwise, she had no great connections or family ties to generate interest in her story. How does one process a collection for a woman who does not meet the traditional criteria for excellence or success or public interest for an archive? Where is the value to the larger historical narrative of our time in preserving the memories of someone who was non-remarkable, or, conversely, someone who may be even too unique to contribute to that greater narrative?

These are the questions I wrestled with when I first came to this collection. As my research progressed, I realized that I faced more questions, and that to come to any understanding that might answer them, I was going to have to research the history of archives and archival processes. Science, the Cold War, Communist China, women, the immigrant experience, all of these issues became part of my thesis, however shallowly I was able to investigate them. Questions of identity and historiography, of power and discourse were explored. In the end, what I found was that a collection that on the outside looked unimpressive and 
unenlightening, could indeed be very valuable, and provide insight into any number of areas of current interest in historical research. This is that story. 


\section{DEDICATION}

To Heather Oriana, my Fellow Cogitator, Motivational Speaker, Personal Coach, Kvetching Coordinator, Ego Lifter, and-most of all-Friend. I could not have done this without you. 
When I came to Portland State as an undergraduate six years ago, it did not take long for me to realize that convenience and practicality had serendipitously landed me in the midst of an amazing educational opportunity. It has been my privilege and my pleasure to study under the professors here for the last five years.

Particularly, I would like to thank Dr. John Ott, who from that first, shellshocked return to academia after fifteen years of non-scholarly pursuits, consistently challenged me intellectually and professionally and stirred an enduring fascination for the study of how we tell history as well as why. Dr. James Grehan also greatly expanded my understanding of both the past and our present interpretations of it and opened a fascinating world of Ottoman and other Eastern history to me. Dr. Karen Carr gave invaluable advice and shared her passion for all things Roman in her fabulous classes, and inadvertently helped me realize that digging through Roman history was not my future.

In the Anthropology Department, Dr. Kenneth Ames proved that Pacific Northwest History could be interesting, and Dr. Sarah Sterling made North American prehistory more than palatable-in addition to sharing her fascination with Neolithic Europe and archaeology in general. Without their input, my work in my history classes would have been much poorer.

Over in the PSU library, Cris Paschild, PSU Archivist and Head of Special Collections, has been a fantastic resource and ally, willing to discuss and debate archives and history and data management at any time and to put up with what 
often seemed to me, at least, the glacial process of accessioning the Kwan Hsu collection.

As a professor and as an advocate, Dr. Katy Barber has consistently gone above and beyond the call of duty, putting out spotfires of panic, coaching our PHiG group through our first grant proposal, and serving as a never-ending font of information and encouragement for the Public History grads these last two years. We were fortunate to have her as a professor and a mentor.

My thanks also go to Jeff Brown, department secretary, for his assistance in everything paperwork related and so much of the other minutiae of graduate life, and to Bee Tranh, who always had a smile and a cheerful word for a frazzled grad student. Dr. Beyler, Dr. Schechter, Dr. Garrison, Dr. Koeneke, all have been helpful and encouraging, and are a large part of why this department is as wonderful as it is.

I took classes from both of my thesis advisors as an undergraduate, and it was truly the opportunity to learn as much as I could from both of them that brought me back here as a graduate student. Dr. William Lang taught me more than most people have forgotten about writing and audience, about the tangled web of history and heritage, and both the joy and the frustration of engaging in history in the trenches. I have had to think about reasons for history and why history, and why I write history and what the point of it all is. Dr. Linda Walton opened the doors of Asian history and especially the Mongol history that ate my brain and not only encouraged and accepted my original research, but was willing to learn with me. She broadened my scope to include world history, helping me to 
see the large webs and connections woven through these various stories we tell. She also provided me with the thesis project that has challenged, stymied, and fascinated me at various times. Dr. Walton's and Dr. Lang's excitement for the many paths history can take is truly infectious. Both of these professors also gave me the great gift of accepting me as a writer. I am forever in their debt.

My family knows how grateful I am to them, for their forbearance and support and cheerleading, knowing all along that in the end, now that is has been Certified, they must put up with my History Geekitude forever.

Last but not least, the last three years would not have been nearly as successful as they were without my fellow grad students, especially Chloe Massarello, and my wonderful PHiG group: Heather Petrocelli, Jeff Baker, Mackenzie Moore, Heather Burmeister, and Doug Kenck-Crispin. You all made me laugh, reminded me of just why my thesis was as interesting as it was, and instructed me in our shared craft. We had an amazing run with the MCCC grant. Here's to the trenches and trenchers we made it through, and here's to the absolutely awesome and kick-ass history we have yet to tell. 


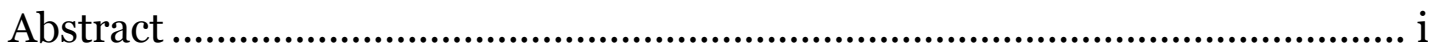

Dedication ................................................................................... ii

Acknowledgements .......................................................................

List of Figures ......................................................................... viii

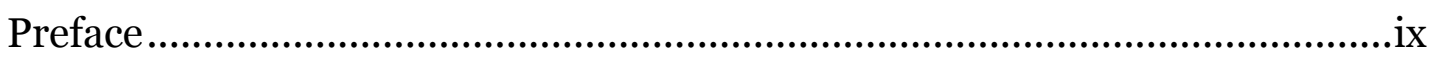

Introduction .................................................................................... 1

Chapter One: In Which We are Ike and They are Tina .............................. 11

“...Archivists must remember the future."

Chapter Two: The Very Model of A Modern Chinese Woman.......................27

"Putting the story together begins not in contemplation of a theory but in an encounter with the evidence."

Chapter Three: The Invisible Woman-Chinese Will Cost You Extra .......... 52

"Your craft is to conjure a social system from a nutmeg grater."

Chapter Four: Re-Membering Kwan Hsu ............................................67

"The archival collection derives not from a conscious act of intellectual creation, as a book or article does, but rather from a gradual accretion resulting from activity over time."

Chapter Five: Eeny-meeny-miny-mo.

"Appraisal imposes a heavy social responsibility on archivists. As they appraise records, they are doing nothing less than shaping the future of our documentary heritage."

Chapter Six: Conclusions?

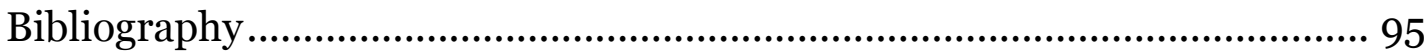

Appendix: Finding Aid for the Dr. Kwan Hsu Papers, ca. 1913 - 1995

Portland State University Archives 
Figure 1 - Kwan Hsu, ca. 1950.........................................................

Figure 2 - Xu Kecheng, Shanghai, ca. 1923-1937.......................................21

Figure 3 - Kwan Hsu, graduation, Morning Star School ca. 1925-26............31

Figure 4 - Kwan Hsu with her parents in Batavia, ca. 1915 ............................37

Figure 5 - Kwan Hsu and car owned by the University, ca. 1932-1936..........42

Figure 6 - Kwan at the Yangtsepoo Social Center, ca. 1932-1936..................49

Figure 7 - Kwan Hsu, ca. 1932.......................................................... 52

Figure 8 - Kwan Hsu, newspaper article, n.d..........................................54

Figure 9 - Dr. Kwan Hsu instructing students at Portland State College.......68

Figure 10 - "Auntie Kwan" and author Amy Tan, ca. 1990...........................81

Figure 11 - Kwan Hsu, Shanghai Institute of Mechanical Engineering.........84

Figure 12 - Kwan Hsu in Beijing, 1986................................................96 


\section{PREFACE}

How does a historian by training, one who has learned to research and work within an archive, accustomed to have her building blocks already somewhat quarried, approach processing twenty file boxes of papers and other records in order to create a viable and interesting collection? How does one decide what to leave in and what to leave out, and, how ultimately to present this person to the world? Is there really a difference between how a historian and how an archivist approaches the creation of archives and history?

When the Kwan Hsu papers became my thesis project, I thought it would be simple. My immediate inclination-as a historian-was to say, "We keep it all. Everything will have value.” Yet as I went through the collection, and as I conducted my research, I began learn that it was not that simple. My own craft of Public History taught me that there is truly a difference between hoarding relics and creating history. And as I made those first passes through Dr. Hsu's papers, the collection appeared to be of interest to a limited few: Dr. Kwan Hsu's friends and a colleague or two-and one graduate student who landed the papers as her thesis project for her MA in History. She had no great successes, did not have a fabulous career. Where was the value going to be in preserving these papers? Who would make use of them, and what could they contribute to the greater sum of historical knowledge? When Cris Paschild, PSU's archivist and Head of Special Collections, asked me those questions three years ago, I could not answer her. 


$$
\text { Donnelly — Shaping the Future Past - } \mathrm{x}
$$

Further complicating my task, the collection itself had been "processed" already before it came to PSU. Dr. Hsu's heir, Carolyn Savage, had rearranged the collection, putting it into order for a manuscript she hoped to publish about Dr. Hsu's life. And while that order was useful to me as I conducted my research, it did not change the heartbreak of finding a heading paper that read, "These letters are from when I was in the mental hospital. What was I thinking?" ${ }^{1}$ only to realize that the letters included in that set had been disassembled into the greater collection, with no indications as to which ones were in this particular grouping. Its natural organization destroyed, I was free to shape the collection as I choseand therein lay another problem. Lastly, I had to deal with the fact that, beyond the theory involved, there is very little written about the practical nuts and bolts involved in processing a collection for inclusion in an archive.

In the end, this project in many ways became one of "What is my duty to history, versus what is my duty to Kwan, herself?” These decisions, perhaps not surprisingly, led to an almost existential experience with my own concepts of history, what it is and how we tell it. And all the while, I feared that I was not going to be able to prove that these assembled papers and ephemera of a diabetic Chinese-American woman were a viable contribution to the PSU archive and a resource for future historians.

History, as I should have known it would, proved me wrong.

\footnotetext{
${ }^{1}$ Kwan Hsu, "Personal Collection”, n.d., Portland State University Archives.
} 


\section{INTRODUCTION}

"For better or worse, it is the historians, at the end of the day, to whom society delegates custodianship of the past. ${ }^{2}$

A Historian

"Historians and archivists are the custodians of memory - the retrievers and preservers of the stories."'3

An Archivist

Everyone has an interesting story to tell, or so popular knowledge would have us believe. Ira Glass, the acclaimed storyteller and oral historian from National Public Radio (NPR), is said to have responded to that particular piece of common wisdom with a blunt, "No, they don't." The same might be said in response to the assertion that all historical information is valuable history. No, it is not. And this was precisely the issue with the papers of Dr. Kwan Hsu. From the outside looking in, Kwan Hsu's papers, while interesting and having definite sentimental value, did not immediately appear to have any real lasting value or ability to make a valuable contribution to make to the collective body of historic knowledge. Not a scientific superstar, not a popular and beloved teacher, far more Dragon Lady than China Doll, she was a woman who lived, endured, and, in the end, died. Her papers were a mishmash of medical bills, diaries, letters complaining about incorrect information in food labels, every advertising flyer she had received in the mail in the last ten years of her life, and unidentifiable

\footnotetext{
${ }^{2}$ Edward Linenthal, History Wars : the Enola Gay and Other Battles for the American Past, 1st ed. (New York: Metropolitan Books, 1996), 139.

${ }^{3}$ Michael Piggott as quoted by Terry Cook, "The Archive(s) Is a Foreign Country: Historians, Archivists, and the Changing Archival Landscape," The Canadian Historical Review 90, no. 3 (September 16, 2009): 534.
} 


$$
\text { Donnelly — Shaping the Future Past — } 2
$$

pictures of people. At first or even second glance it did not appear that her life held enough interest nor did there appear to be enough material in her papers to make the collection itself a useful contribution to the Portland State University (PSU) Archive-or any other archive, for that matter. 4

Given recent emphases in social and public history-reading against the grain, searching out the heretofore silent voices of the past, those hidden in political and national narratives or lost in the cracks of the discourse of a dominant culturethis negative view would seem to be a heretical assessment of the papers of an immigrant minority woman. The proliferation of identity-based institutions such as the Museum of the Native American, the increasing importance of gender and social group based archives, the growth of oral history and folklore, and the rise of community history collectives-all of these trends would seem to support both common wisdom and current historical thinking. But ultimately, Ira Glass is right: Not every story is interesting. Neither are the accumulated papers and other detritus documenting a single person or event immediately valuable simply because of their existence. Here, too, it is up to the historian, as it is to Mr. Glass and his fellow radio producers, to unearth the details from the evidence, to tease out the value from the information, and then to assemble those parts into something cohesive, something coherent-something historical.

History becomes, then, a bridge between the many kinds of evidence left to us by the past and the present, with the historian as interpreter, though hardly an unprejudiced one. This historians have known for a long time, that we are "led by

\footnotetext{
${ }^{4}$ Paschild, Cris. Personal conversation, 2010.
} 


$$
\text { Donnelly — Shaping the Future Past - } 3
$$

our present day concerns," forcing us to an open acknowledgment of our own subjectivity. ${ }^{5}$ But what about the evidence with which the historian works? How objective or subjective are the materials from which we build our histories? Many if not most historians eventually spend their time in an archive, whether private, personal, or public institutions. We find receipts, letters, and diaries, and with knowledge and careful research, extrapolate. Historians understand many things about archives, including the fact that "records are left by people who lived in the past, but-and this is the tricky part-the records are extant in the present."6 Knowing this, smart historians will pull archived evidence apart and look at it from as many angles as possible, studying the obvious as well as the non-obvious connections for what might be learned from them. We understand the incompleteness of the record that has been handed down, that there are lacunae which may forever hinder our knowledge even as we learn to read against the grain, mining archives for greater insight into other stories beyond the dominant narratives. We understand, too, that our "authority" as historians comes not only from our evidence and our reading of that evidence, but also from our ability to say, however literally, that we have been there; we have read (or seen) the evidence for ourselves.7 But far too often, historians forget that there is another component to our work: the hand of the archivist.

\footnotetext{
5 Richard Evans, In Defense of History, [American ed.]. (New York: W.W. Norton, 1999), 75, 216.

${ }^{6}$ Joyce Appleby, Lynne Hunt, and Margaret Jacob, Telling the Truth About History (New York: Norton, 1994), 253.

7 Carolyn Steedman, "'Something She Called a Fever' -- Michelet, Derrida, and Dust (Or, in the Archives with Michelet and Derrida.)," in Archives, Documentation, and Insistutions of Social Memory: Essays from the Sawyer Seminar, ed. Francis Blouin (Ann Arbor: University of Michigan Press, 2006), 13.
} 


\section{Donnelly — Shaping the Future Past — 4}

In spite of the amount of time spent in archives, many if not most historians enter the archive as if it was "a foreign country." Referring to this lack on the part of historians, Dr. Terry Cook, a Canadian archivist and historian stated:

"[An archive] may be [a country]...that they visit frequently - but perhaps mainly as tourists passing through, focusing on their guidebooks, intent on capturing appealing views, but overlooking their surroundings, not talking to the local inhabitants about what they do, thus failing to understand the country's real character and animating soul." 8

This lack of understanding of the real character and animating principles of archives can leave historians with a near belief in archived records as pristine, as if this text, this box of letters, that archaeological material record simply lay in wait for discovery, its conception entirely organic. We have too often mistakenly assumed "archival perfection" in the past, saw archivists as "august arbiters of fact." ${ }^{9}$ But what we have to realize, first and foremost, is that the archive containing those records, like the records themselves, also exists in the present of its creation—and again in the present of its maintenance and its creators and archivists. Though it has its own life through use and maintenance, an archive or a collection is not organic in and of itself.

\footnotetext{
${ }^{8}$ Cook, "The Archive(s) Is a Foreign Country," 503. Dr. Cook makes deliberate reference with the title of his article to David Lowenthal's book, The Past is a Foreign Country, launching his own arguments from the fact that it was the very act of preserving the past, or archiving it, that set it apart and "ensured that the past was perceived as different from the present, more foreign than familiar, and, equally, that the archiving act itself imbued the newly collected and accessible documents with different meanings and, accordingly, different uses."

${ }^{9}$ David Lowenthal, "Archives, Heritage, and History," in Archives, Documentation, and Institutions of Social Memory: Essays from the Sawyer Seminar, ed. Francis Blouin (Ann Arbor: University of Michigan Press, 2006), 194-194.
} 


\section{Donnelly — Shaping the Future Past - 5}

An archive, like any set of historical records, is constructed, created, managed, and organized. From their creation (or their discovery), collections of any kind are organized: by their originators, and if they continue to exist, by the vagaries of time and elements if nothing else. Later, they are often organized by those who donate them to an archive, whether inadvertently, as a family member removing treasured photos before giving a sibling's collected papers to someone else, or by those anxious to control the history presented within a particular set of records..$^{10}$ Once brought to attention for preservation, the material within any collection is assessed, appraised, and assembled. Decisions are made throughout this process as to what will be saved, what will be culled, in what order those items saved will be preserved-all decisions that affect any future research done in these records. As Dr. Cook further states, "as archivists appraise records, they are doing nothing less than determining what the future will know about its past: who will have a continuing voice and who will be silenced. Archivists thereby co-create the archive."11

This is not a good or a bad thing; it simply is. Human beings are builders, construction experts. We build our worlds inside and out with words and images and with physical materials. Society and culture are structured in a way that preserves power and privileges for some groups, hoping to pass specific sets of values down through the generations. Historical information builds nations and

\footnotetext{
${ }^{10}$ Most often associated with totalitarian regimes or shady presidents, many people do not realize that their own attempts to present their loved one's best face is motivated by the same need to control their image, their representation in history.

${ }^{11}$ Cook, "The Archive(s) Is a Foreign Country," 504.
} 


\section{Donnelly — Shaping the Future Past - 6}

establishes borders both national and personal. We construct our own identities, past, preset, and future, from the materials we are given. Archives, however constructed they may be, are also a human endeavor, a product of time and place, of creators, both originating and archiving. These blocks of archived memories, of textual records, are some of the major building blocks with which we build our history, our societal memory and our collective cultural heritage, making them a form of received knowledge, if neither pure nor divine in origin. This received knowledge is much of what makes us human, not only that we remember, but that we share those remembrances with future generations, whether as legends or history or simply as information. "Stories," it has been written, "are one of the major ways in which human intelligence assigns meaning to life."12 And it is as historians, telling the stories of the past, that we attempt to be certain that the societal memory with which we build is as complete as possible.

But the fact of the matter is that time and space are limited-as is interest. An archive that is simply a jumbled collection of papers and notes will only be useful to those (such as graduate students working on a single thesis project) who dig into it. There is no way to make it useful to the broader public unless some understanding of what is in the collection is available, and some means of accessing the organized information is provided. For a Marie Curie an archivist will dig through all kinds of mundane and unimportant papers. But for a diabetic Chinese-American professor of biophysics with no real name recognition even

\footnotetext{
${ }^{12}$ Appleby, Hunt, and Jacob, Telling the Truth About History, 233.
} 


\section{Donnelly — Shaping the Future Past — 7}

within her own field? Not so much. Every record does not have historical value. Not every story is interesting-at least, not today.

The challenge, then, for the archivist becomes not just processing the archive and mapping the materials into accessible format, but making the archive useful to the greater public, giving the archive a reason to exist beyond the frail "everyone's story can be an interesting story" spiel that children are told and that they hold to as adults. In order to make it so, however, the archivist must also understand a great deal about the creator of any collection. In this particular case, it meant understanding who Kwan was and how she fit into the many communities and groups to which she belonged. This was an individual who was shaped also by the culture and complexities of her times, both in China before and during World War II, and in the United states, as a

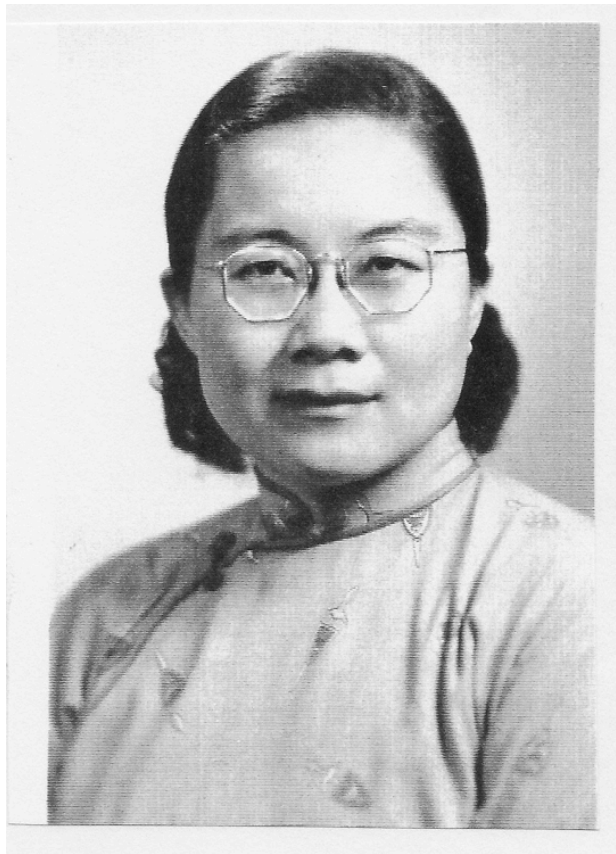

Figure 13 - Kwan Hsu, ca. 1950. This picture was most likely taken while Kwan was a student at the State University of Iowa. (Image from the Kwan Hsu Papers, courtesy PSU Archive.)

woman, an exile, and an immigrant. She was a scientist during a time of both great upheaval and great holding on to the values of the past, where science intended to become more gender-inclusive, and yet became almost more a man's world than it had been before. All these issues needed to be addressed in order to understand the value (if there was any) to this collection. 
Donnelly — Shaping the Future Past -8

It is an unarguable truth, as well, that no collection can ever truly re-member the creator. The Kwan Hsu who created this collection will not be the Kwan Hsu this collection represents into the future. From the young woman who came over from China in 1947 to the professor emeritus at Portland State to the woman who wrote in her diary that she regretted giving her life to science, this woman could not be fully known from this incomplete collection. There are aspects of her life that can be recreated, and there are bits and pieces of her thoughts and experiences that can be assembled into a whole. But as with any representation of a person constructed by a historian, the result is a facsimile, not the actual person.

Complicating this further is the fact that very little is written on the actual process of archival appraisal. Articles on archival theory and practice aboundand can sound as arcane as medieval alchemy manuscripts to one uninitiated in their language and practices. But most skip over the actual, "this document we kept, this we didn't" part of the process. On the historians' side, there is a great deal written by historians on what they found in archives, and discussions about how best to search an archive. But as to the actual process of accessioning a collection and how that might affect the information gained from it, very little is written-or even known, perhaps.

In order to address these questions and remedy that gap a little bit, this thesis will follow the following format. First, the literature review will address the history of both history and archives and their relationships. Chapters 2 and 3 will address the specific areas where Kwan's papers were found to have value: 
Donnelly — Shaping the Future Past — 9

women's archives, science archives, and Chinese-American archives. Throughout, Kwan's biography will shape and frame the discussion with events and insights from her life, since ultimately she is the person this collection will represent throughout the future past. Chapter 4 will discuss important issues which shaped the actual process of appraisal, how the identity that will carry Kwan's past forward into the future was defined and then created by selecting what records were and were not kept within the collection. Chapter 5 will discuss actual decisions made in the process, why some items were discarded and others kept. Appendix A is an annotated finding aid for the collection, which will lay out the current state of the collection at the time of this writing.

How does one shape the collection of a woman who was far more often an anomaly and an outsider than an insider, a woman who labored in the trenches throughout her career but was known for no great discoveries or experiments? A single childhood letter from the author Amy Tan to her "Auntie Kwan" seemed to indicate that the collection's value was going to be purely sentimental. Kwan had no major accomplishments like other groundbreaking female physicists, nor did she have a standout record at Portland State. She came here, she seemed to accomplish her goals, and then she retired. Her diaries and her experiences with the mental health system seemed to be of some value at least as a curiosity, but that was a few months of her life. Yet Kwan was also one of the first foreign women to receive an American Association of University Women (AAUW) International Study Grant after World War II, and she remained active speaking at AAUW events for a number of years. Within Oregon, Kwan started the 
Donnelly — Shaping the Future Past - 10

Biophysics program at Portland State College (now PSU), and in an era when many universities would not hire women faculty let alone a minority, PSU not only brought her here, they hired her for a tenure-track position. As a professor, she taught her classes and conducted research, and in addition was an active member of the international community and a driving force behind PSU's current connections with China. She was a liaison between Oregon businessmen and the newly opened Chinese markets in the 1980s. As a child in China, her experiences provided a unique window onto life on the fringes of an elite family-and the occupation of Shanghai by Japanese forces in World War II.

In terms of her career, Kwan fills a space that most women in sciences filled in the past century: a laborer in the trenches. Unlike other scientists such as Dr. Chien-Shun Wu and Dr. Fay Ajzenberg-Selove, who found careers and fame almost in spite of their circumstances, Kwan's name never came up in Nobel Prize talks, whether for inclusion or later for unjust exclusion. At the very least, Kwan's diaries of her school years and her documentation of her job search provide a look into the world of unheralded research assistants and the other areas in which educated women of science labored for so long, areas which are both lacking in primary source material and in written histories. In short, once history is examined and the collection of papers is re-examined in light of that history, there is a great deal after all to be learned from this woman's life. 
Chapter One: In Which We ARE IKe AND They ARE Tina

“...Archivists must remember the future."13

Born in 1913 in Guangxi Province, part of the newly established Republic of China, Kwan Hsu lived in China until she was thirty-four. The first record in her collection that connects her to the United States is her receipt for the "Alien Head Tax", dated September 9, 1947, a tax collected by the government of the United States and the Philippines as part of an effort to "regulate the immigration of aliens into the United States and Philippine Islands." Within the collection of Kwan's papers that make up the project for this thesis, the records for her life in China are perhaps understandably the most sparse. Not only was she constrained by baggage limits as she crossed an ocean with no idea what kinds of quarters she would have for the next few years, but she also intended to remain in the United States only until she had finished her schooling, for five or perhaps six years. And it was not until later in her life, when memory problems began to plague her, that she became almost obsessive about saving every record and every piece of paper that came into her life.

\footnotetext{
${ }^{13}$ Terry Cook, "Remembering the Future: Appraisal of Records and the Role of Archives in Constructing Social Memory," in Archives, Documentation, and Institutions of Social Memory: Essays from the Sawyer Seminar, ed. Francis Blouin (Ann Arbor: University of Michigan Press, 2006), 178.
} 
Donnelly — Shaping the Future Past - 12

What sorts of things did cross the ocean with Kwan? She brought a program from her grammar school that lists her name as graduating second place in French and a few other documents, but mostly she brought pictures. Pictures of a young girl in glasses with a shy smile, photos of a happy college co-ed clowning around with her girlfriends, leaning on the school's car (a sign of wealth and privilege that Kwan wrote about later in her life), and standing solemnly with her graduating class. ${ }^{14}$ Photocopies of other pictures indicate that her brother, $\mathrm{Xu}$, may have taken a number of family photos back with him after Kwan's death. ${ }^{15}$ But these fragments of a personal history cannot give meaning alone to a collection. Within our nation, identity archives do their best now to collect and preserve the stories of all individuals, regardless of notoriety or dominant cultural notions of "value." Yet it cannot be denied that linking to a famous or successful (or at least notable) personality, or to some great tragedy or series of events collectively assessed as "memorable" helps to both bring attention to a collection and lends legitimacy to its inclusion in future historical narratives. But for Kwan, there was nothing obvious in her pictures and few random documents that indicated significant historic value. Worse, in a world with increasingly more historical material and information to be sorted through, creating a premium on space and time, there is a greater demand for physical records to have obvious immediate value. A collection's viability can be directly linked to its ability to generate traffic to an archive or website, or its ability to draw in funding for the

\footnotetext{
${ }^{14}$ Kwan Hsu, "I Remember Papa”, n.d.

${ }^{15} \mathrm{Xu}$ went through his sister's papers at least peripherally, before handing the materials over to Carolyn Savage, Kwan's executor and heir in the United States.
} 
Donnelly — Shaping the Future Past - 13

archive. Further explorations of Kwan's papers did not reveal anything that might be of immediate interest to a particular audience.

Historians often want to assume value, however miniscule, in all records simply because they are historical-sort of like the weird aunt at Grandma's funeral insisting that Grandma's troll doll collection is valuable simply because it has aged and is part of the family heritage. But heritage is not always or even often the same as history. Blind, unthinking, heritage considers anything worthy of saving that is older than itself. Historians have been trained to be more selective, but when it comes to documents and text, can also lose their way given the general cultural logophilia of Western civilization. But when processing or appraising a potential collection, even historians need to think more like archivists.

But aren't archivists and historians much the same? Don't they receive almost the same values and training? Aren't archives the basis of modern history? Perhaps they were the same, once upon a time, when most archivists were simply sidetracked (or unemployed) historians. Perhaps archives were the foundation on which German historian Leopold von Ranke built this modern house of scientific, source-based history, but post-modernity has wrought changes upon the building, imposed modernist additions whose style was not always appreciated-and those changes impacted more than just the profession of history, pushing archivists and historians in vastly different directions. 
Donnelly — Shaping the Future Past - 14

What's history got to do with it?

Archives are as ancient as settled civilizations. From the collected cuneiform tablets of the Hittite Empire to the leaves upon leaves of Dynastic chronicles in China, to the vast collections of medieval manuscripts in Europe, those in power have kept records of that power in some manner-and destroyed other records, whether of previous regimes or their own. Not every record and not every event was recorded, and value came from selection rather than value leading to selection. Inclusion in an archive made a record important and authentic, not the record's mere existence. ${ }^{16}$ As such, from keepers of essential records, archives and archivists gradually evolved into adjudicators of documentary authority-and finally, the authorizers of authority itself. Backed by the authoritative documents, secure in their locked and access-controlled archives, rulers held onto their power, while landowners and other privileged souls maintained those privileges. Upon their foundation of authoritative texts, religious dogma was maintained and with it, for Europe, at least, "theocratic tyranny over vast reaches of monotheistic time and space." ${ }^{17}$ In the modern age, archives were the very root of nationalism; their existence understood in more recent historiography almost purely as "the institution of state power." 18 Archives such as these would have no room for the pictures or papers a young woman leaving her country found

\footnotetext{
${ }^{16}$ Francis X. Blouin and William G. Rosenberg, Processing the Past: Contesting Authorities in History and the Archives, 1st ed. (Oxford University Press, USA, 2011), 18.

${ }^{17}$ Lowenthal, "Archives, Heritage, and History," 194.

${ }^{18}$ Carolyn Steedman, "'Something She Called a Fever' -- Michelet, Derrida, and Dust (Or, in the Archives with Michelet and Derrida.)," in Archives, Documentation, and Insistutions of Social Memory: Essays from the Sawyer Seminar, ed. Francis Blouin (Ann Arbor: University of Michigan Press, 2006), 6.
} 
Donnelly — Shaping the Future Past - 15

valuable. Historically, only those whose lives and records were deemed "important" by those in control could count on being included in an archive, a situation that still exists today, though admittedly with a far more relativistic definition of "important." The discourse of the dominant remained unchallenged, even as the records on which it was built were manipulated, teased, weeded, and, at times, outright erased. ${ }^{19}$

And yet, it was this very same perception of archives as arbiters of authority that led to the birth of modern history. If Ranke had not had confidence in the authority and accuracy of the archives from which he began to research what became modern history, there would have been no purpose in his efforts. Modern historians know this all too well in a post-modern age of relativism and multiple voices of history. Historical authority has needed a different footing in recent years, and it is not a footing that has been easily gained-or held on to-though it is one that many times yet resides in the details unearthed from archives. But in the "halcyon days" before Vietnam and postmodernism, before the "new" social history and the rise of other social sciences derailed our national narrative, inverting the exceptionalism and manifest destiny of the white European settlers of the United States to give that status to the conquered, the non-white, and the non-male, before this sea-change in the intellectual world, historical authority rested rather readily on the shoulders of the archives. ${ }^{20}$ And since most archivists

\footnotetext{
19 Cook, "The Archive(s) Is a Foreign Country."

${ }^{20}$ Oscar Handlin, Truth in History (Cambridge Mass.: Belknap Press, 1979), 82-83. This is a rather deliberately flippant reading of Oscar Handlin's comments in his book, but I believe that his lament reveals, however inadvertently, the insular and exclusive nature of historical studies of the
} 
Donnelly — Shaping the Future Past — 16

were historians by training and archivists by vocation, the marriage had been and seemed assured to be a long and fruitful one.

Appearances, however, can be deceptive. And, as happens all too often, the partners changed, growing apart, without quite realizing it, at least on history's side, if Cook is to be believed. Tom Nesmith, another archivist, goes further, comparing the break up of archivists and historians to the marriage of Ike and Tina Turner-implicitly if not explicitly casting historians as Ike. It was a convincing if uncomfortable comparison, especially as he detailed the ways in which Tina Turner turned to history to rebuild her own sense of self and career. ${ }^{21}$

Celebrity marriages aside, what happened to this comfortable union of archives and archivists and historians? At the risk of radically simplifying things, history splintered and fragmented for social, cultural, and political reasons. Historians Joyce Appleby, Lynn Avery Hunt and Margaret Jacob credit the G.I. Bill and increasing numbers of working class whites, of minorities and women gaining access to higher education, and many of those seeking careers in history. More importantly, they documented the fall of science as a god, the relentless rolling back of the ideal of pure science, untainted by political machinations or

day. There were reasons for his lament, and good ones, and we have yet to restore that solid, overarching sense of national unity. However, to everything its season, and I find myself wondering if the current trend toward interconnected world history is not a perhaps subaltern backlash amongst academics against the fragmenting of our national mythologies. Whether that is true or not, Handlin has much in his book to say that is good, but his lament for "the good ol' days" of history when it was a small, controlled, contained world telling a unified history of western civilization is for me an excellent example of the changes in archives and history.

21 Tom Nesmith, "What's History Got to Do With It?: Reconsidering the Place of Historical Knowledge in Archival Work," Archivaria., no. 57 (2004): 1-28. 
Donnelly — Shaping the Future Past — 17

political agendas. ${ }^{22}$ Where, then, could modern, scientific history turn for its authority? Without science, on what foundation could any solid history be built? Even as he failed to understand the "tribalism" of his own cloistered approach to the craft, noted historian Oscar Handlin blamed what he called "tribal histories" on those historians who threw over the traces of the formal restraints of traditional history, many of them from the same groups that Appleby et al lauded as new entrants into the profession. In spite of his blinkered attitude to the new historical horizons, Handlin fully grasped the potential richness of the more complex history which could now be told, even as he warned of the dangers inherent in allowing the professional guide for "importance" to be what is now usually defined as heritage. His legitimate fear was that historians would only write "fantasy and soap opera tales" rather than the "epic" approach that history deserves-what he saw as presentist polemic rather than true, historical insight. ${ }^{23}$ Richard Evans, too, warned that scholarship would "suffer" if "political or moral aims became paramount. ${ }^{24}$ Michael Kammen was much more pragmatic: "The landscape of the past changed its appearance as the meaning of the past altered; and so the uses of memory altered accordingly. Memories were value-laden, and

\footnotetext{
${ }^{22}$ Appleby, Hunt, and Jacob, Telling the Truth About History, 146-147, 160-197. We are still feeling the backlash of the "fall" of science from its pedestal of incontrovertible truth today, most evident in our current political climate, where politicians and other public figures feel free to deny the results of scientific inquiry. "Theory" has become a dirty word, synonymous with "unproven" truth. It is interesting to watch the issues in many ways that history has grappled with and found new ways to deal with in terms of vetting source material and accepting multiple stories, now playing out on our national (and not-so-national) political stage.

${ }^{23}$ Handlin, Truth in History, 402, 417. Though this is hardly the first time in our history that marginalized and believing-themselves-to-be-marginalized groups have presented and represented their history as they wished them to be told, with varying degrees of mythology and historical verity, there was always the solid refrain of our national purpose and destiny within which these stories had to be framed. See Kammen, pp. 121-125 for one case in point.

${ }^{24}$ Evans, In Defense of History, 188.
} 
Donnelly — Shaping the Future Past - 18

therefore underwent adjustment when a transformation occurred in the dominant system of cultural values."25

Throughout this upheaval, historians kept their focus on the destruction of their historical authority, the cheapening of both the validity of their conclusions and their voices. They ignored in large measure if not entirely the fact that the same revolutionary and postmodern forces were driving changes within archives themselves. If archives were mentioned in any of the historiography books I read about the recent crisis in history, it was in passing, or in the development of new identity archives. No one took the time to address how the changes in culture and technology and methodology may have affected the construction of those all important archives. Even as archivists, too, were reeling from discussions about the impermanence of any meaning, postmodernism threatening the very idea of a record, let alone an archive of records and the cultural power it suddenly represented, historians remained wrapped up in their own postmodern crisis.

Archivists, as could be expected, have a different story of this breakup, and though perhaps not combustible enough to generate a trajectory like Ms. Turner's post-Ike career, it is a tale of which historians seem almost entirely ignorant.

Past archival practices validated official and political histories over those of operations and marginalized at best personal papers. Those same practices prevented archivists from developing a way to truly authenticate non-textual documents, especially when text documents were so often "well-organized,

25 Michael Kammen, Mystic Chords of Memory: The Transformation of Tradition in American Culture (Random House Digital, Inc., 2011), 162. 
centrally controlled, and officially sanctioned" when compared to oral traditions, audio, or images. ${ }^{26}$ This led, again, to an archive focused on the political and powerful, over all others-and yet, the archivist was perceived as a neutral actor in the historical record.

Archives constructed and controlled the historical conversation to a large part simply by dint of their authority and their contents. But then came the modern era and the nearlogarithmic proliferation of records-and the shift of the concept of archivist as one who authenticates and keeps authoritarian documents, to one who manages documents. Rooted

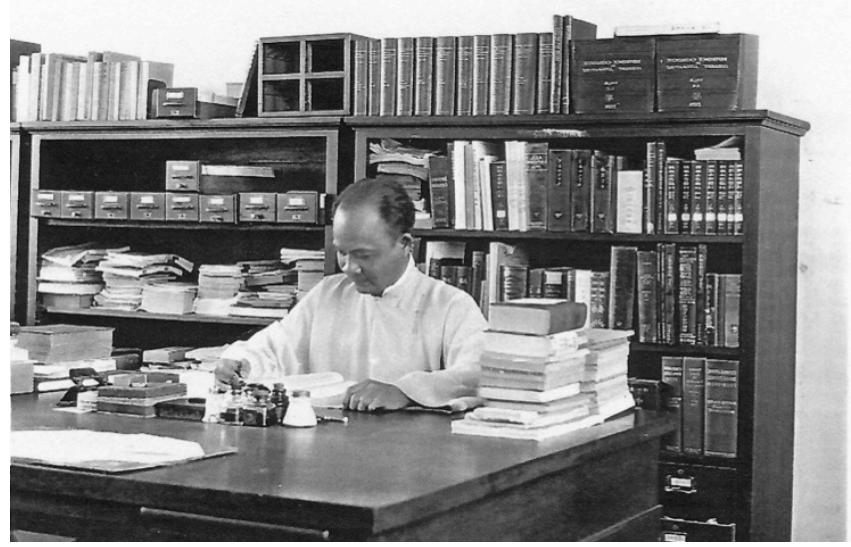

Figure 14 - Xu Kecheng,, Shanghai, ca. 1923-1937. Kwan's father, was a university librarian in Shanghai, before World War II. (Image from the Kwan Hsu Papers, courtesy PSU Archive.) in our western obsession with the written word and text-based, scientifically investigated (or investigable) evidence over all, as early as the late 1940s archives and archivists had begun to move away from the concerns that occupied historians. ${ }^{27}$ Establishing themselves as a separate profession, archivists focused less on the historical content of their archives and more on the management of that data. "Hierarchical fonds" and "provenance" became the ruling factors, and archives were to be preserved by

\footnotetext{
${ }^{26}$ Cook, "The Archive(s) Is a Foreign Country," 527.

${ }^{27}$ Blouin and Rosenberg, Processing the Past, 43.
} 
Donnelly — Shaping the Future Past -20

archivists as the operating record of the organization that created them, cleaned and ordered and rationalized, ready for "legal, administrative, fiscal, and research uses." ${ }^{28}$ Archivists also became data managers by necessity, in some cases, as the sheer bulk of records being generated increasingly became an issue. Forms and bureaucracy and populations exploded, and today the sheer number of records created, whether digital or analog, means that some form of data management is an absolute must in any archive.

Theoretical papers on the archival profession in the late 1990 s and early 2000 s were filled with conversations and jargon-laden statements such as "Evidence means patterns of processes, aims and mandates, procedures and results, as they can be examined...Archives appraised and described...will reflect the community of primary purposes---not only as the relationships of concernson the basis of common functional origin." 29 With archives focused on managing the flood of documentation rather than assessing for future historical value, articles on appraisal worried that "appraisal in concert with other archival tasks, benefits from process and standards: but if it is drained of its human connections, it runs the risk of becoming a formulaic exercise of procedures detached from its purposes and goals, where compliance becomes a comforting refuge from the uncertainties of choice.”30 Discussions of retention schedules,

\footnotetext{
28 Richard Cox, No Innocent Deposits: Forming Archives by Rethinking Appraisal (Lanham Md.: Scarecrow Press, 2004), 238.

${ }^{29}$ Angelika Menne-Haritz, "Appraisal or Documentation: Can We Appraise Archives by Selecting Content?," The American Archivist 57, no. 3 (1994): 537-538.

${ }^{30}$ Barbara L. Craig, "Setting the Students' Bearings and Balance in Appraisal," Archival Science 5, no. 2-4 (September 2006): 401.
} 
Donnelly — Shaping the Future Past — 21

metascheduling, primary and secondary values of information and evidence, the need to understand which "records of enduring value were likely to reflect the essential features of an institution in all of its administrative and procedural complexity" became the coin and the language of the realm. The focus was not on understanding the history of any era and therefore the foundations of the creation of a record and how it might represent the current world to the future, but to look rather to the functional relationship between a "record and the agency which produced it." ${ }^{1}$ Throughout, the myth of the neutral archivist remained paramount-for historians and other users of the archives, not just archivists themselves. ${ }^{32}$ Yet even the simple task of organizing a collection "masked much of the messiness of records (and their creating entities) from researchers, presenting instead...a record collection...that never existed that way in operational reality." Archivists were neither neutral nor passive in the creation of their collections. Records were not simple documents, but were created in “complex processes and multiple discourses." 33

Terry Cook, Canadian archivist, is a leading scholar in the re-evaluation of the archivist's role in creating collections, and has perhaps done more than any other to strip archival language of its abstruseness and simplify the arguments within the archival profession. Because "the neutral, impartial archive of classic archival theory, is, in reality, a place of order, control, hierarchy, reflecting the power of

\footnotetext{
31 Blouin and Rosenberg, Processing the Past, 88-89.

32 Joan Schwartz, "Archives, Records, and Power: The Making of Modern Memory," Archival Science 2, no. 1-2 (January 1, 2002): 173-174.

33 Cook, "The Archive(s) Is a Foreign Country," 528.
} 
Donnelly — Shaping the Future Past — 22

the...sponsoring institution...that called it into existence and continues to pay the bills." 34 Cook also championed a re-evaluation of the methods of appraisal focused upon the reality of the archivist's role and that power connection between the institution housing the archive and the archive itself. "Macroappraisal," as the method was called by the National Archives of Canada, who developed the strategy,

"focuses on the functions of government per se, emphasizes the interactive functioning of citizen and group as much as that of the state, encompasses all media rather than privileging text, searches for multiple narratives and hot spots of contested discourse rather than accepting the party line, and deliberately seeks to give voice to the marginalized, to the 'other,' to losers as well as winners." 35

This was a major shift away from the idea that the organizational power of its creation conveyed value to a record and an acknowledgment that what is truly at stake is power. History is written by the victors, for controlling memory and remembrance are means to controlling and retaining power, and archivists were one of the tools in use.Today, aware of changing social trends in the use of their materials and the power of an archive to support or marginalize other histories, more and more archivists are aware of and discussing the reality that "the major act of historical interpretation occurs not when historians open boxes, but when archivists fill the boxes, by implication destroying the 98 percent of records that do not make it into those or any other archival boxes." ${ }^{6} 6$

\footnotetext{
${ }^{34}$ Cook, "Remembering the Future: Appraisal of Records and the Role of Archives in Constructing Social Memory," 174.

35 Cook, "The Archive(s) Is a Foreign Country," 528.

${ }^{36}$ Schwartz, "Archives, Records, and Power," 173-174.
} 
Donnelly — Shaping the Future Past — 23

Historians, or so the archivists believe, remain rather oblivious to these facts. Yet this does not change the fact that for historians, "how the archivist forms and presents the historical record is itself a historical problem." 37 No longer can historians have the luxury of not understanding how the archives upon which they depend are created and maintained.

Layered over all this is the fact that within the United States exists a near religious conviction concerning the truly exceptional nature of our national character and a dedication to the value of the individual over the communal. In a nation founded on the rejection of tradition and an embrace of the new and the future, leaders and scholars were more than willing to take their history with a large dose of mythology. "Others appeal to history," one British scholar scoffed. “Americans appeal to prophecy."38 Michael Kammen's own comment was just as pithy: "We prefer plasticized apotheosis to historicized memory developed in judicious doses."39 In short, the United States likes its heroes, and it likes them with virtues and their status as role models intact. Even as the modern thrust of history has shifted from the previous focus on records of the powerful and the elite, as a society there remains a focus on the exceptional, whether positive or negative. Other points of views are pursued in an effort to fill in the lacunae of the dominant historical strains, but most often by first searching out memorable or successful people with stories to tell. George Washington Carver. Harriet Tubman. Crazy Horse, or Amy Tan. Often, success grants credibility, and for non-

\footnotetext{
${ }^{37}$ Blouin and Rosenberg, Processing the Past, 160.

${ }^{38}$ Sidney Smith, as quoted in Kammen, Mystic Chords of Memory, 43.

${ }^{39}$ Ibid., 28.
} 
Donnelly — Shaping the Future Past — 24

traditional archives, a successful candidate brought credibility to the enterprise of collecting papers and telling a story-and could drive essential public notice and funding opportunities for an archive to tell stories of the less successful.

Or, conversely, interest is created by tragedy, a story as glaringly negative as any other history seeks to be positive. Chief Joseph is an appropriately tragic hero, as is Sitting Bull. The story of the destruction of Native American cultures is slowly becoming one of the accepted histories, reluctant as much of the nation is to fully accept it. The Jewish Holocaust in World War II has long been sacralized; the unjust internment of Japanese-American citizens is also being incorporated into the national narrative. There are museums for tenements occupied by European immigrants, slave quarters at Williamsburg, and the nation celebrates (however reluctantly) a slain civil rights leader. In short, a sufficiently great tragedy or accumulated negative background can be the catalyst for an archive or a museum, granting reason to be remembered. It is only in the past generation or so that a group's lack of inclusion in the dominant historical narrative has come to be accepted as valid reason (or tragedy) for searching out that voice, and they must still compete for time, space, and funding with every other archive.

Where did the papers of an only mildly successful Chinese-American professor of biophysics fit into this narrative? She was not a refugee, but rather a woman trapped by circumstance. She was not a superstar, nor was she entirely downtrodden. She was moderately successful, but not spectacularly so. She published a few papers, but she didn't seem to have been great at anything she did. In a time when identity and gender based archives are proliferating, she is 
Donnelly — Shaping the Future Past — 25

not obviously outstanding-there are others more impressive and with better records than her-most especially Dr. Chien-Siung Wu, another "should-havewon-a-Nobel-prize" Chinese American scientist, whose background was similar to Kwan's. Kwan was from a wealthy, intellectual family of some renown within China, however peripheral her membership, but she did not contribute to that family's legacy. She had wanted to become the Madame Curie of China, and if she had returned, she might have been. But she did not, and so the search began for something worth keeping in her story.

Carolyn Savage's unpublished manuscript, "Looking West Toward China: the Life in Letters of Kwan Hsu," provided some insight into the larger events in Kwan's life, as did several essays Kwan had written for a creative writing class she took in the early 1980 . Though the essays focused on her early life, it would be an unfounded assumption to believe that she placed a higher value on those years than others. They were assignments for a class, and, also, age tends to look back toward youth with nostalgia. There was no reason to assume what value that Kwan might have assigned to the papers or that period in her life. But used as a launching point for research for her life, that research in turn pointed to the places where the papers she left behind would have the most value. It was a wandering path: modern China, the Cold War, Science, Women in science in the U.S., Asian American immigration in the United States. Some concept of the major advances in science during her career, too, was necessary. It was from these subjects that answers were unearthed (and it was definitely plural rather 
Donnelly — Shaping the Future Past — 26

than singular) to the question, "Why would anyone really be interested in the papers of a diabetic Chinese-American woman?”

Ultimately, the research necessary to gain understanding of her times led very directly to the conclusion that Kwan's papers truly were an archive worth preserving. There is very little research on women such as Kwan, immigrant intellectuals who arrived before and during the Cold War. Specific research on Chinese American scientists in the Cold War is scarce, as is research on her particular group of student immigrants. Her Christian, western education and her experiences dealing with the mental health industry can provide valuable information for a number of scholarly trajectories. Her diaries recording her experiences as a woman graduate student and as a woman in science are invaluable. On the social history front, Kwan's later life is a wonderful documentation of the reconnection of an expatriate with her family after a generation of Chinese communism had separated them.

In short, Kwan's history would shape her archive, even as her archive shaped the history that would be told about her. 


\section{Chapter Two: The Very Model of A Modern Chinese Woman}

"Putting the story together begins not in contemplation of a theory but in an encounter with the evidence." 40

Contrary to popular belief, when it comes to archival collections, possession does not convey ownership, 9/10s or less, of either the contents or the person whom the contents represent. While the historian comes to an archival collection (or collections) hoping to create knowledge and understanding of the past from the documents and other ephemera within, the archivist has to gain knowledge and understanding in order to select the documents and ephemera which will create the collection itself. Historians seek truths and knowledge of the past, but archivists have their own "historical imperative" to seek out records, to protect those records, to make them both known and available as "carriers" of the past to the future. ${ }^{41}$ As they make these choices and selections, they are literally (no pun intended) choosing the information that will be preserved for the future."

Appraisal imposes a heavy social responsibility on archivists...they are doing nothing less than shaping the future of our documentary heritage." 42 Yet, in the recent past, archival training has focused more exclusively on "organizational theory, complex systems, information science, communications..."43 It has been such a focus that when Terry Crook wrote about "macroappraisal," stating that "it focuses on the functions of governance rather than the structures of governance,"

\footnotetext{
${ }^{40}$ Handlin, Truth in History, 127.

${ }^{41}$ Nesmith, "What's History Got to Do With It?," 5.

${ }^{42}$ Cook, "Remembering the Future: Appraisal of Records and the Role of Archives in Constructing Social Memory," 169.

${ }^{43}$ Blouin and Rosenberg, Processing the Past, 93.
} 
Donnelly — Shaping the Future Past -28

and that it "emphasized interactive functioning" between people and the state and did not privilege text over any other sort of record, he could honestly state that by adopting this method of appraisal Canadian archivists were taking a "distinctive lead in reconceptualizing the archive."44

In the first assessment of value, whether macroappraisal or not, little was found in Kwan's materials that argued for preservation. There were few encounters with fame, fortune, or success, either her own or others. Reading through her collection, without understanding the history behind it, the apparent paucity and mundanity of records from her years as a scientist and an instructor did not have an obvious value. Neither did her long, involved argument with the Baylor Alumni Association and the Shanghai Institute of Mechanical Engineering, the modern incarnation of Kwan's alma mater, the University of Shanghai, over the founding of an alumni center there for ex-pat alumni such as Kwan. There was more hope for her diaries of her experiences with Donner Labs and Dr. Cornelius A. Tobias as a graduate student in the 1950s, but an investigation into the records of those labs did not find Kwan's name mentioned. Her path through gaining refugee status in the 1950s during the height of the Cold War may have had a more obvious value, but those records constituted a small fraction of the collection. It quickly became obvious that before decisions could be made about Kwan's collection, the world that shaped Kwan's history had to be understood.

\footnotetext{
${ }^{44}$ Cook, "Remembering the Future: Appraisal of Records and the Role of Archives in Constructing Social Memory," 174-175.
} 
Donnelly — Shaping the Future Past — 29

This research took a wandering path: modern China, the Cold War, Science, Women in science in the U.S., Asian American immigration. A basic understanding of the barest fundamentals of the Chinese language were necessary in order to look up characters and understand names and dates in her papers. Ultimately, focusing on her early years in China, while most likely the smallest portion of the collection, was the simplest starting point, and quickly revealed that Kwan's early life in China, her years at the University of Shanghai, and her experiences in Japanese-

occupied Shanghai during World War II were critical to

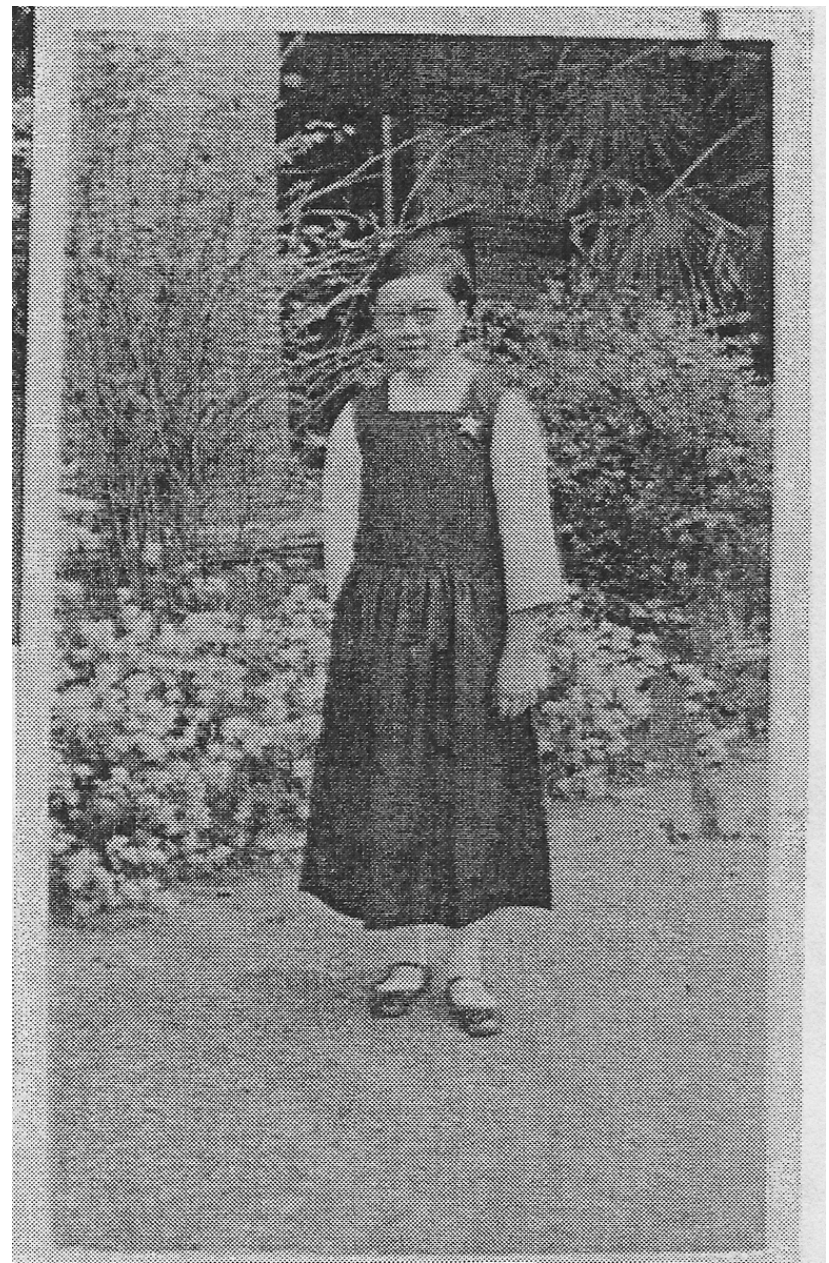

Figure 15 - Kwan Hsu upon her graduation from Morning Star School, Shanghai, ca. 1925-26. (Image from the Kwan Hsu Papers, courtesy PSU Archive.)

understanding the woman and the rest of her life-and thus to whatever shape her collection would eventually take.

The culture that shaped Kwan's early years, that of China, is borne of the oldest continuous civilizations known to man. And yet Kwan lived in a time when radicals were seeking to reshape that culture, though without losing two of the 
Donnelly — Shaping the Future Past — 30

most important ideals in that culture: responsibility to and for family, and the traditions of intellectuals in civil service. Because of their paucity, it can be difficult to see the value in keeping these few pieces of evidence. Yet upon investigation, the value of the insight they give into the woman who created the rest of the collection becomes clear, and, therefore the inclusion of these records is essential in the final assembly of this collection.

With historical records dating back through four thousand years of organized civilization, China is one of if not the oldest ongoing culture known. For over the last 2000 years, the foundation of that culture has been in Confucian thought and practice. Though Confucius himself lived in the sixth century B.C.E., and his disciples were spreading his philosophical teachings before his death, it was not for another three hundred years that his essential virtues truly began to be woven into the foundations of Chinese civilization. Beginning with the Han Dynasty (201 B.C.E. -220 C.E.), Confucianism became the philosophical basis of government and infused the culture with its humanist (if highly patriarchal) tenets, the belief that living correctly and performing the proper rituals would lead to a good life for the individual and a stable country for all. Central to those concepts was the idea that any individual (a definition not quite exclusively limited to men) was capable of learning and being taught, and anyone could be civilized if they studied the proper texts and learned to act properly. From this humanistic beginning, education and learning became the paths to both civilized behavior and civilization in China. 
Donnelly — Shaping the Future Past - 31

In the nineteenth century, Confucian scholars grappling with how to move China's ancient culture into the modern era, adopted the idea of "Confucianism as the 'substance' of Chinese culture, providing moral direction, while accepting Western science and technology as the 'application', a practical expression of modernity." 45 Even in the throes of the May Fourth revolution in the early $20^{\text {th }}$ century, a movement which upheld such radical notions as the equality of the sexes and co-education, knowledge was still held to be the path to civilization, though now it was Western knowledge that would lead the way. Like the $19^{\text {th }}$ century scholars, many intellectuals and other elites believed this knowledge could transform China into a modern nation-but they still wanted a transformation that would not destroy the unique national character of China. Kwan, as evidenced in her personal history and her collected papers, exemplified this ideal: an educated individual raised in the Confucian traditions of family and social responsibility - and yet, at the same time, anomalously a woman and a Christian, with a Western Christian education.

Rooted in the Confucian ideal of education as the route to civilized behavior is the educated civil servant. The first Chinese imperial university was established in 124 B.C.E., the first civil service exams in 605 C.E. when Emperor Yang of the Sui Dynasty introduced the jinshi examination degree. ${ }^{46}$ China throughout the centuries (and her many Emperors) was a land ruled by bureaucrats long before

\footnotetext{
45 Lee Rainey, Confucius \& Confucianism the Essentials (Chichester, West Sussex, U.K.; Malden, MA: Wiley-Blackwell, 2010), 177.

${ }^{46}$ Charles Holcombe, The Genesis of East Asia, 221 B.C.-A.D. 907 (Honolulu: Association for Asian Studies and University of Hawai'i Press, 2001), 47; Mark Edward Lewis, China Between Empires: The Northern and Southern Dynasties (Harvard University Press, 2009), 250.
} 
Donnelly — Shaping the Future Past - 32

modern bureaucracies arose. These educated civil servants dominated East Asian culture for hundreds of years, part of the reason for the dominance of Chinese culture and the Eastern association of "civilization" with Chinese intellectual tradition. In Kwan's family, both of her parents' families were from that intellectual elite class. Later, after her father married his second wife, the famous Huang Yanpei became Kwan's step-uncle. Huang, an industrialist and an educational reformer from another intellectual family, was widely regarded as the founder of vocational education in modern China. In addition, Kwan's mother, too, was educated, perhaps as a result of the first wave of reforms intended to modernize China at the end of the $19^{\text {th }}$ century. 47 These traditions, both of education and civil service, therefore, were integral to understanding Kwan's life.

Notions of family, too, were essential to Chinese culture and life. Confucianism (and Confucius himself) was born during the Warring States period, a time of violence and chaos in Chinese history. Fifteen hundred years of civilization was threatened with the fall of the Zhou Dynasty and China's descent into a mélange of squabbling, fighting fiefdoms and tiny kingdoms. As in any era where the elites battled amongst themselves, the common people suffered most: pestilence, famine, conscription, taxes-all plagued the people of China. Into this chaotic time, Confucius taught that moral actions would lead to a "proper and civilized society." The most important relationship he believed must be honored

\footnotetext{
${ }^{47}$ Nanxiu Qian, "Revitalizing the Xianyuan (Worthy Ladies) Tradition: Women in the 1898 Reforms," Modern China 29, no. 4 (October 1, 2003): 402. According to an obituary Kwan had of her maternal uncle, "Leo" Chao [Zhao], their family was Muslim. Kwan's uncle converted to Christianity in the early 1900s, and attained some notoriety as an evangelist. His children immigrated to the United States as well, and could perhaps shed more light on the family's history. Both her parents were from Kweilin, or Guilin City, in Guangxi prefecture.
} 
Donnelly — Shaping the Future Past - 33

by moral actions was the notion of "filial piety." The parent-child relationship was the first and most fundamental social relationship, and honoring that relationship would teach someone loyalty and duty beyond their home, as well.48 This would, in turn, contribute to a stable and well-managed empire-or nation, as it was by Kwan's day. Part of this tradition would involve upholding family honor, and providing for the family. Educational success was another part of this value system, especially in families such as Kwan's, who were from the traditional intellectual elite class, where their very social status was dependent upon education. Viola Huang, Kwan's “cousin-in-law,” a United States citizen who lost her citizenship when she married her Chinese husband, explained this concept simply for an audience of United States church women: "The height of human happiness, as the Chinese conceive it, is 'five generations under one roof." Ms. Huang went on to credit this emphasis on family and family duty with allowing the Chinese to survive the many wars that had wreaked havoc on the land in the years she was there. Family takes care of one another.49 Kwan's parents died before she left China, and her brothers remained there. But even though she lost all contact with her immediate family after the 1949 Revolution, in the Chinese tradition of Confucian filial piety, family remained an integral part of who Kwan was as a person and the success-or failures-in her life.

And, as with any good puzzle, there were the pieces of Kwan's history that did not easily fit into the image of a traditional Chinese woman, past or present.

\footnotetext{
48 Rainey, Confucius \& Confucianism the Essentials, 28.

${ }^{49}$ Huang, Viola, "About China”, ca 1950, 1, Kwan Hsu Papers, PSU.
} 


$$
\text { Donnelly — Shaping the Future Past — } 34
$$

Kwan's parents' marriage was a non-traditional love match, and her maternal uncle, Leo Chao, was a Christian missionary. $5^{\circ}$ Kwan's own Christian faith was an integral part of her life throughout her adult years. According to Kwan's papers, both her parents were educators, her mother a principal at a grade school and her father a principal at various Chinese high schools. Her mother, Zhao Liangheng, died of typhoid when Kwan was three years old, and Kwan traveled with her father to the various schools where he worked, dressing in boy's clothing and living in dorms with him. Several years after his first wife's death, Kwan's father, $\mathrm{Xu}$ Kecheng, moved with his daughter to the thriving city of Shanghai, and there entered an arranged marriage with Huang Jian, the sister of Huang Yenpai.

50 An obituary published in a United States' religious magazine stated that Mr. Chao came from a Muslim family, which would indicate that Kwan's mother, too, was Muslim. This adds yet another layer to the interest in Kwan's background for future researchers. 


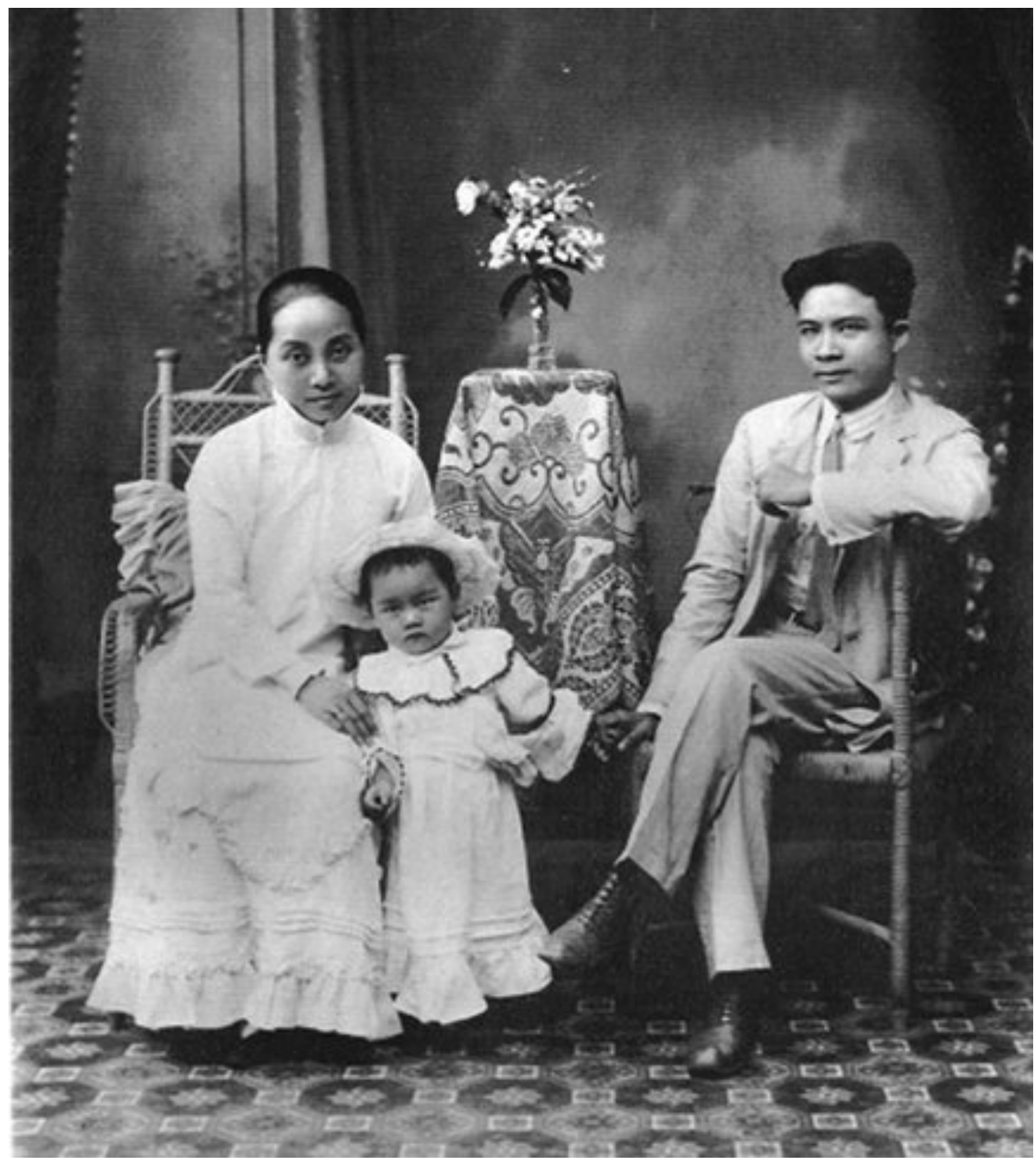

Figure 16 - Kwan Hsu as a child with her parents in Batavia, ca. 1915. Her mother, Zhao Liangheng (left), was pregnant with their second child when she died of typhoid in 1916. (Savage, Carolyn. Looking West Toward China: Discovering the Life and Letters of Kwan Hsu. Unpublished manuscript. Kwan Hsu Papers, Portland State University Archive. Image from the Kwan Hsu Papers, courtesy PSU Archive.)

Kwan's unusual upbringing was also shaped by the reforms and revolutions rocking her homeland throughout the early twentieth century, most specifically 
Donnelly — Shaping the Future Past — 36

the May Fourth movement, a cultural upheaval that began with a huge student protest in Peking on May 4, 1919..$^{11}$ As the movement took root and spread, intellectuals determined to modernize China's culture came to the fore, their main goal transforming China to fit into the industrial world. They would do this by learning from the West while defending China's sovereignty-if not every aspect of her ancient culture. Beyond political reform, as in 1898, social reforms such as equality of the sexes, education, and science were cornerstones of the May Fourth movement, which was intent on bringing China fully into the company of modern nations. This was the dominant cultural paradigm during much of Kwan's teen years, one that saw science as an absolute necessity for the future of China-and one in which women and girls were encouraged to step out, get an education..$^{2}$

The many years she lived in Shanghai would also have had their impact on Kwan's identity. The first of the Opium War treaty ports to open for business, by the twentieth century Shanghai had become a cosmopolitan metropolis with a vibrant cultural and intellectual life. Shanghai became "the Paris of the East." Chinese cinema was born here, and intellectual writers such as Lu Xun wrote about and argued social realism and the "New Culture" amongst themselves and

\footnotetext{
${ }^{51}$ The rallies were originally called to protest the Treaty of Versailles' Article 156, which instead of returning Germany's concession in the Shandong peninsula to China as had been promised in order to bring China in as an ally to France and England, ceded them to Japan. The demonstration was the beginning of a cultural revolution in China,

52 Kwan's uncle Huang developed an ambitious plan to bring "vocational education" to the lower classes. In his eyes, a "properly run school" taught mathematics, engineering, and business with a scientific bent. See Yeh, Wen-Hsin, "Huang Yanpei and the Chinese Society of Vocational Education in Shanghai Networking," in At the Crossroads of Empires: Middlemen, Social Networks, and Statebuilding in Republican Shanghai, ed. Nara Dillon (Stanford Calif.: Stanford University Press, 2008).
} 
Donnelly — Shaping the Future Past - 37

in the universities. In the foreign concessions, 8100 acres at the heart of the city, Russians, Americans, Jews, and other European nationalities lived, contributing to the exotic blend of cultures.53 By the time Kwan and her father moved to the city in the early 1920s, Shanghai was the most important financial capital in East Asia.

These two complex environments, then, were what Kwan Hsu became a part of when she arrived in Shanghai as a child: the cultural, intellectual and nationalistic foment of the city itself, underlaid with labor and commerce and foreign dealings, and Huang's own determination to create an educational system that would "close the distance between the cultured and the employed." 54 Kwan added a third environment to this rich mix: her own education, especially her experiences in Christian schools. 55

Kwan, whether through her father's influence or her famous step-uncle's, attended private Western schools throughout her life. Her middle and high school years she studied at St. Mary's School for girls, a Catholic boarding school in Shanghai. Kwan's letters and diaries describe an unpleasant relationship with her stepmother. Her father's new wife wanted to marry Kwan off when she turned thirteen, evidently resenting the money he spent to educate a girl. Working as a librarian at this time, Xu Kecheng wanted his daughter to continue

\footnotetext{
${ }^{53}$ Kwan writes of receiving a "Baccalaureate in French" in addition to her high school diploma, the degree being awarded by the General Consul of the French Concession-the highest ranking French diplomat in the city. She also notes that her father snuck her the money for these lessons. In her later curricula vita, she lists language fluencies in Chinese, English, French and a reading knowledge of German and Russian.

${ }^{54}$ Yeh, "Huang Yanpei and the Chinese Society of Vocational Education in Shanghai Networking."

${ }^{55}$ Kwan Hsu, "Letter to Mrs. Tobias and Eve", July 23, 1953, Portland State University Archives..
} 
Donnelly — Shaping the Future Past - 38

in school because he felt an education was the only legacy he could give her. Living on campus to escape hostility at home, by age sixteen Kwan was teaching in less privileged schools to help pay for that education; she spent long hours each summer tutoring students and giving private lessons in algebra, geometry, and piano.

After high school, Kwan attended the University of Shanghai with the intention of getting a degree in physics. ${ }^{6}$ Her cousin said later that she had wanted to become "the Madame Curie of China." As one of the first generation of Chinese women to be admitted into a coeducational higher education institution, Kwan's experience here, too, is unique and valuable. The University also ran the Yangtsepoo Social Center and a village and community center in the industrial areas near the campus, providing education, medical care, and places of amusements for the working poor. 57 Here, Kwan could provide genuine community service in keeping with her step-family's social status while remaining within the University's narrow sphere of Christian influence.

At the University Kwan found an identity and sense of connection that she did not seem to have elsewhere. Kwan herself converted to Christianity while she was in college, a conversion which set her further apart in many ways from her stepfamily, who did not convert, but brought her closer to what was most likely

\footnotetext{
${ }^{56}$ Founded in 1906 by a group of Baptist Missionaries fleeing the Boxer Rebellion, in thirty years, the college grew from a the last two years of high school with one year of college instruction to a fouryear university, a full-grade middle school, an elementary school, a School of Commerce located in downtown Shanghai. Women were admitted in 1920, the first of the missionary schools in Shanghai to allow co-education. See White, Francis Johnstone. The Story of the University of Shanghai: From the Year 1906 to the Year 1934. 1935.

${ }^{57}$ John Hipps, History of the University of Shanghai. ([N.p.]: Board of Founders of the University of Shanghai, 1964).
} 
Donnelly — Shaping the Future Past - 39

her family of choice, her friends and fellows at the University. It may also have been a means of identifying with her mother, whose brother was also a Christian, having become a missionary in his own country shortly before Kwan was born.

Kwan earned her Bachelor's degree in Physics in 1936, and she returned to the University a year later, expecting to teach. It was a wealthy school; in an essay written in 1983 , Kwan describes how isolated their campus was, so much so that the students never took part in many of the protest movements that other students did, protests which were a vital part of the ongoing social and cultural revolution in China. In 1935, during student demonstrations against Japanese Imperialism in Shanghai, Kwan was one of two students, one male and one female, selected by Dr. Herman Liu, the president of the school, to attend these demonstrations. Kwan and her fellow student held up a banner with their school's name in order to demonstrate that Shanghai University had been there. The president of the school, Dr. Liu, had been reluctant to participate in the demonstration, but students from other schools had threatened to attack his campus if they did not. Kwan later wrote of feeling odd that she had been chauffeured to an event where it was obvious that most students had either walked or biked. 58

\footnotetext{
${ }^{58}$ Hsu, "Demonstration in Front of City Hall and President Dr. Herman Liu."
} 


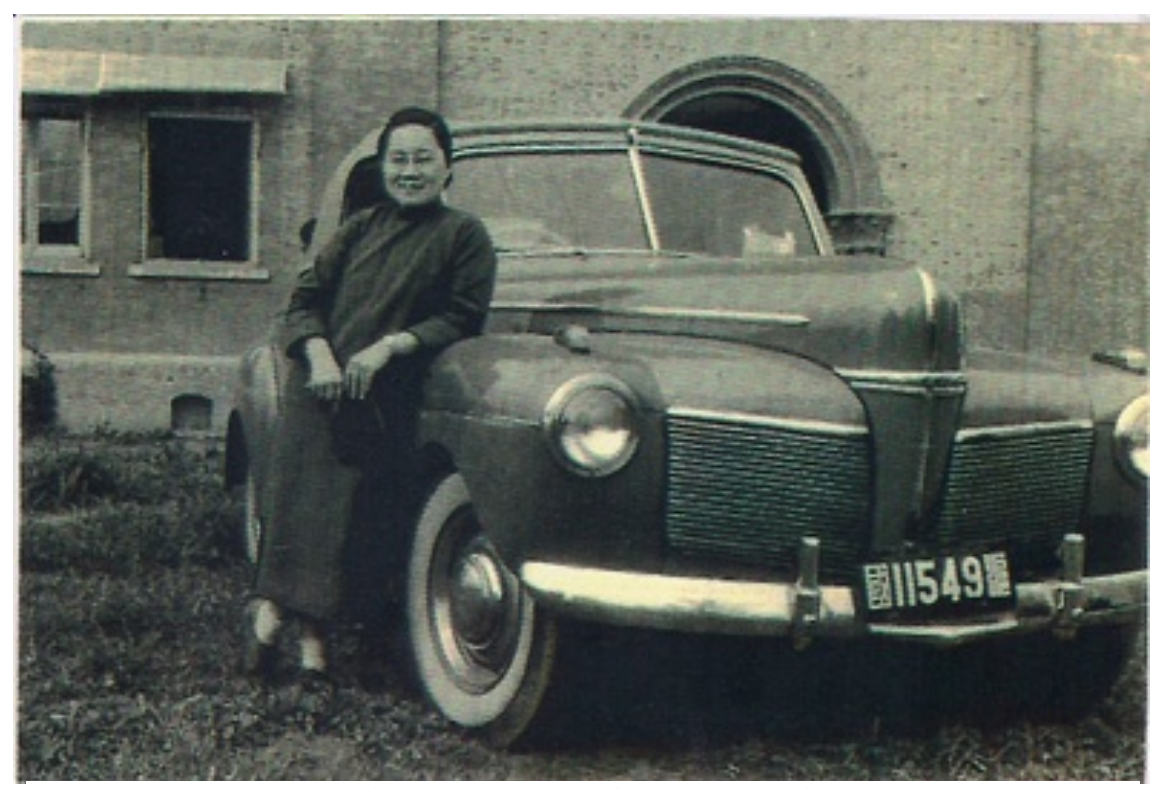

Figure 17 - Kwan Hsu, leaning against the car owned by the University of Shanghai, ca. 1932-1936. (Image from the Kwan Hsu Papers, courtesy PSU Archive.)

However isolated her school, Kwan and the rest of her community could not have avoided the cultural backlash China experienced during the 1930s against that educated "revolutionary" woman, an ideal generated within the May Fourth movement. In the cities, particularly Shanghai, this new ideal of womanhood provided a provocative and exotic image not exactly in tune with traditional Chinese values.59 Politically active and concerned with life beyond the home, this modern woman was later cast as a negative representation of the social and political upheaval of the $1920{ }^{60}$ Attempts by the Guomindang to restore cultural order in the 1930 included investing rather in the iconic image of the "selfsacrificing woman," the traditional Chinese woman focused on home and family

\footnotetext{
${ }^{59}$ Dal Lago, Francesca, “Crossed Legs in 1930s Shanghai : How 'Modern' the Modern Woman?," East Asian History (2000).

${ }^{60}$ Paul Bailey, Gender and Education in China: Gender Discourses and Women's Schooling in the Early Twentieth Century (New York: Routledge, 2007).
} 
Donnelly — Shaping the Future Past — 41

as the ultimate in cultural authenticity. ${ }^{61}$ Beyond the stereotypes and media images of the day, educated women who believed in their right to individuality and careers faced, as did so many of their sisters worldwide, the "contradictory expectations" of the freedom that came from education and access to life outside the home, yet which had to be navigated within the limits of China's conservative, patriarchal, Confucian culture. ${ }^{62}$ Raised in a family that believed in education, given an education by her own father, believing in science and the values of the May Fourth movement to save China, Kwan still belonged to this ancient culture. Furthermore, she had embraced a Western religion that, for all that it offered education to women, also saw women as subordinate to men, meant to serve first and pursue their own success second-and true success was never quite separated from the ideal that she should first seek to support the success of any males in her life.

Kwan Hsu graduated in 1936 from the University of Shanghai with a B.Sc. in physics, with honors. Planning to go abroad for graduate education "in a couple of years" after she had earned enough money, she could not have foreseen the outbreak of the Sino-Japanese war later that year, nor how it would wreak havoc with her own plans. ${ }^{63}$

\footnotetext{
${ }^{61}$ Ibid.

${ }^{62}$ Ling-Ling, Lien, "Leisure, Patriotism, and Identity: The Chinese Career Women's Club in Wartime Shanghai," in Creating Chinese Modernity: Knowledge and Everyday Life, 1900-1940, ed. Peter Zarrow (New York: Peter Lang, 2006).

${ }^{63}$ When the Battle for Shanghai began on August 13,1937, the Japanese faced what should have been an overwhelmingly superior Chinese army dug in and ready to do battle for this jewel among cities. Chiang Kai-Shek sought to divert Japanese from fighting in northern China by attacking their forces in the Shanghai area. But his best foreign-trained troops failed to break Japanese defensive lines. The Chinese Air Force missed their bombing raids on the Japanese navy in the
} 
Donnelly — Shaping the Future Past — 42

Though Shanghai fell into Japanese hands in 1937, until the fall of the foreign concessions in 1941 life in most of Shanghai continued to be somewhat normal. The presence of the foreign concessions with their access to the outside world and their insistence on at least nominal neutrality for the first years of the Japanese occupation, in combination with Shanghai's deep ties to the hinterlands, meant that residents had both access to resources and to the outside world that most cities occupied by an opposing army would not have had. ${ }^{64}$ Within Shanghai, the citizenry never "mobilized" in terms of resistance; assassinations and other acts of terrorism took place between the Japanese, the collaborators, and the Chinese resistance, but these acts remained in the "Badlands" or no-man's-lands between the foreign concessions, on the fringes of normal society-a battle between "professionals" that left the citizens themselves sidelined.65 Though bombs were dropped and the Japanese soldiers were always present, while many lost their businesses and livelihoods, and displaced residents filled the streets of the

harbor, dropping their bombs instead on Shanghai itself. The Japanese quickly marshaled their naval and ground forces, and along with artillery, devastated the Chinese positions. With total losses of up to 250,000 men, the Chinese soldiers fought a three-month-long defensive battle through the city. But no matter how heroic their stand, they were ultimately outflanked by the Japanese, and in November, began a wholesale retreat towards Nanjing. Shanghai became an occupied city.

${ }^{64}$ Christian Henriot and Yeh, Wen-Hsin, In the Shadow of the Rising Sun: Shanghai Under Japanese Occupation (Cambridge UK ;;New York: Cambridge University Press, 2004). Henriot argues that the popular historiography of wartime Shanghai as gudao, an isolated island abandoned by the Chinese government during the war, helpless and surrounded, is a simplistic argument which exists in a dichotomy of "resistance vs. collaboration," and which provides a cover against charges of collaboration for the city. After all, Shanghainese went about their "normal lives" under Japanese occupation until the fall of the foreign concessions in 1941-1942, something that the rest of China did not have the luxury of doing. The reality, they contend, is far more complex, given Shanghai's unique culture and history. The advent of civil war almost immediately after the end of the Sino-Japanese was meant that there was no corresponding "post-war" period in China as there was in Europe and the United States, and many of the players involved had good reason to embrace the black and white image of the past and move on toward future concerns.

${ }^{65}$ Ibid. 
Donnelly — Shaping the Future Past — 43

concessions while refugees from the country flooded the city, Shanghai maintained an atmosphere of normalcy that allowed many of her residents, like Kwan, to go about their lives almost as if there was no war. Social organizations and merchant associations mobilized to feed and care for the refugees in their midst. Papers were printed, films were produced, and commerce took place. Scholarships were awarded. Women's magazines, media, and literature flourished. ${ }^{66}$ Children went to school, and parents-and other family providerswent to work.

Kwan Hsu spent the first months of the war helping her father take care of the Chinese soldiers fighting in the city. ${ }^{67}$ Two months into what would be a three month battle, troops from Guangxi, Xu and Kwan's home province, arrived to reinforce the original Chinese troops. There appear to have been some connections between Kwan's father and the commanding general, Li Zhongrenenough that Zhongren apparently stayed with $\mathrm{Xu}$ while directing the fighting in Shanghai. Whatever their ties, when the Chinese army abandoned Shanghai Kwan's father had to leave with them. Her father's departure coincided with the return to "normalcy" in Shanghai proper, but for Kwan it meant a radical shift in responsibilities. Rather than her father's favorite child, only concerned with her

${ }^{66}$ Huang, Nicole, "Fashioning Public Intellectuals: Women's Print Culture in Occupied Shanghai (1941-1945)," in In the Shadow of the Rising Sun: Shanghai Under Japanese Occupation, ed. Christian Henriot and Yeh (Cambridge UK; New York: Cambridge University Press, 2004).

${ }^{67} \mathrm{Hsu}$, "I Remember Papa." Her father quit his job to join the army, and she sewed uniforms for poor soldiers. General Li Chung-Ren, general of the Nineteenth Army lodged in their family home, yet another indication of the upper class ties of the Xu family. Kwan wrote years later that she still had the gifts General Li's wife had given to her during their stay. General Li evidently left in such a hurry that he left behind his sword and uniform. Kwan had to dispose of them herself, doing so at night to avoid the Japanese. It is one of the few mentions in her papers that directly reflects the danger she might have been in from the Japanese army. 
Donnelly — Shaping the Future Past — 44

own future, she was now responsible for providing for her younger brothers and her stepmother, who still did not care for her. ${ }^{68}$

Throughout the decade in which the Japanese occupied Shanghai, Kwan was the main breadwinner of her family. Yet unlike many women who spent their days standing in line for the basic necessities of life, searching for work (or a male protector), Kwan's elite status allowed her to continue teaching at the University and often several different high schools at once. In her award from the AAUW, they list her as “.... Chinese instructor in physics who repeatedly had to reconstruct 'from nothing' the lab equipment for her classes as her apparatus was confiscated by the enemy or lost when the university was vacated; now catching up with new developments in nuclear physics." ${ }^{69}$ She cared for her step-mother and later for her invalid father. She paid for her two younger brothers' education and saw at least one of them through college during those years. Years later she wrote, "Everyone was in fear of the brutality of the Japanese soldiers. Many adult males had left Shanghai. I was considered the one who was capable of making any decision."7o

\footnotetext{
${ }^{68}$ Current research indicates that Huang Yanpei, the other male head of household in her family, was not in Shanghai during the war; he seems to have been in Chongkung with the Nationalist government.

${ }^{69} \mathrm{Hsu}$, Kwan Hsu to Mrs. Tobias and Eve. The letter from which this information is taken was written to the wife of one of her professors when Kwan was studying for her Ph.D. in physics at Berkeley. It is entirely possible that the focus on her teaching in the letter is a direct result of her need to prove to these friends that she had a great deal of teaching experience before she came to the United States, experience that she was not and had not been given credit for by either her professors or her employers here in the United States. Further research into the contents of the collection may yield additional insights into her experiences during the war.

${ }^{70}$ Hsu, "I Remember Papa."
} 
Donnelly — Shaping the Future Past — 45

In the latter years of the occupation, Kwan and her "best friends" administered a scholarship fund for students and teachers. ${ }^{71 t h i s ~ m e a n t ~ t e s t i n g ~}$ the children who applied, grading those tests, and then dispensing the scholarships. It also meant vetting the teachers who would receive "loans" that would allow them to buy supplies for their classrooms. Kwan states in her letter that the funds for these scholarships came "from the public." It was common in Shanghai to hold dances or other public events, charging admission or taking donations, and then donating that money to relief work somewhere, so this could be one way the money was collected. Another manuscript makes reference to "media" who helped with the scholarships, though what publication or group that might have been is not known. It also seems most likely that her family connections with Huang Yanpei, as well as her ties within the international Christian educational community, may also have given her access to and provided a means to acquire the funds for these scholarships. She takes pains to mention that they were very choosy about the schools to which they sent the children, and the scholarship fund had enough social clout that she writes, "Schools would get angry if we said they weren't good.” For one young woman from Guangxi province, stepdaughter of the sister of an important provincial official, this implies a great deal of both responsibility and social power in the wartime communities of Shanghai.

What these details and no doubt further research reveal is that Kwan Hsu's World War II experience was, in spite of her elite status, a typical and patriotic

\footnotetext{
${ }^{71}$ Hsu, "Letter to Mrs. Tobias and Eve."
} 
Donnelly — Shaping the Future Past — 46

experience for a woman in Shanghai. She was a woman being faithful to her family, her community, and her duty in the face of the Japanese occupation. Throughout the war, even beyond events in Nanjing, images of rape and humiliation paralleled the nation of China's experiences at the hands of these not-so-foreign invaders. ${ }^{72}$ Somehow, the reaction of this iconic representation of the ideal Chinese woman to being invaded became the symbol of resistance against the Japanese, as if being so very perfectly, properly Chinese could hold or even turn back the Japanese war machine. In Shanghai, this feminized image was particularly associated with what resistance movement did exist and the messages were even more direct. Rather than out and out resistance or activism, women were urged to "do their traditional jobs, but do them better."73 Shanghai's mothers and daughters and wives were exhorted to be good mothers and daughters and wives: frugal, concerned with their children's proper behavior, the comfort of their husbands and sons (and brothers), and the maintenance of that perfect Chinese femininity. In fact, Shanghai was notable for its lack of an organized citizens' resistance to occupation. Somehow, the ordinariness of day-to-day life became heroic. 74 Kwan's experience of the Japanese occupation of Shanghai, for all that it was privileged by her social status (if such a term can be applied to any such experience), was part of this feminized

\footnotetext{
${ }^{72}$ Ibid.

${ }^{73}$ Glosser, Susan, "Women's Culture of Resistance' : an Ordinary Response to Extraordinary Circumstances," in In the Shadow of the Rising Sun: Shanghai Under Japanese Occupation, ed. Christian Henriot and Yeh, Wen-Hsin (Cambridge UK ;;New York: Cambridge University Press, 2004).

${ }^{74}$ Ibid.
} 
face of the resistance-and a part of the woman who came to the United States in the years after the war.

These, then, are the worlds that Kwan Hsu lived in, the places that shaped the woman who arrived in the United States in August of 1947 and paid that Alien Head Tax. These were lessons learned by the woman who studied for a doctorate in the United States, first at the University of Minnesota, then at (then) State University of Iowa, and lastly, at University of California Berkeley. She had been

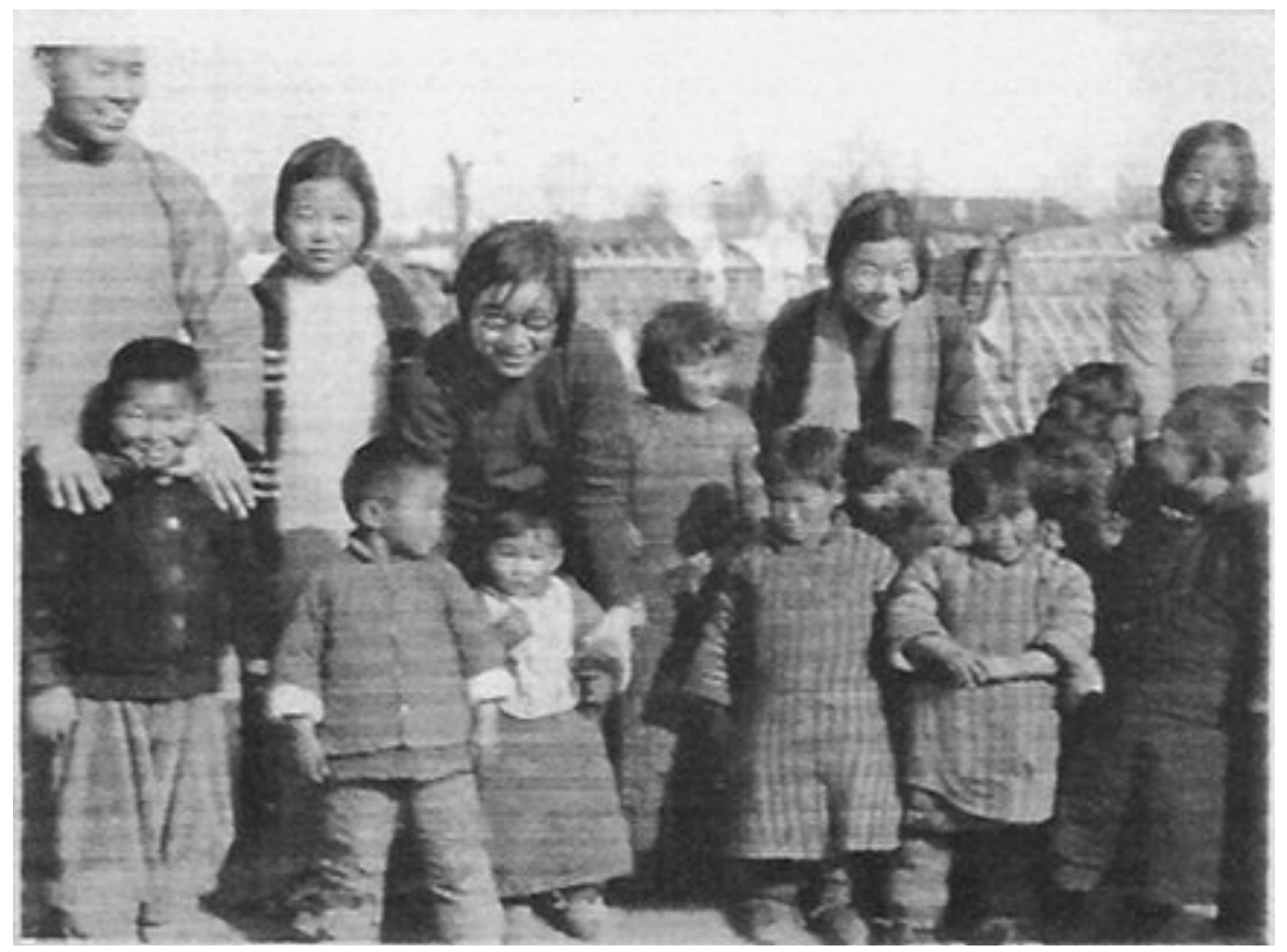

Figure 18 - Kwan at the Yangtsepoo Social Center, run by the University of Shanghai, ca. 19321936. (Image from the Kwan Hsu Papers, courtesy PSU Archive.)

a proper Chinese woman, even as she followed through on her father's dream of a scientific career and a good education for his daughter. Kwan was a devout 
Donnelly — Shaping the Future Past — 48

Christian; among her souvenirs from the trip over on the S.S. Gordon in 1947 is a program for a church service. Her arrival in the U.S. for further study was a special reward for Kwan from the school and the church to which she had been so faithful. She was a woman who understood hard work, taking care of others first and not always good at finding ways to serve and fill her own needs. Tradition and culture, science and service, and hanging in there and making the normality of life were the ways in which Kwan had learned to cope and survive through tough times. Reflections of this belief can be seen in her determination to succeed in the United States in spite of the obstacles placed in her way, and in her complaints to supervisors about taking care of everyone around her so much that she could not get her own research done. Scorned at home by her step-mother, she had found a home at her university, the one place where she could be among many others who, like her, were Chinese, and yet Western Christian in belief. Once she arrived in the United States, she never seemed to be able to reproduce that camaraderie. She remained constantly an outsider in her various communities, an alien. Her best friend in the United States was another Chinese woman, a war bride, also displaced in time and culture and learning to adapt.

What does this have to do with Kwan as a part of American history? As Him Mark Lai, a historian, has said about Chinese-American history, "The Chinese are a part of American society and they need to be studied as part of U.S. History, but because of the overseas connections, they need to also be studied as part of 
Donnelly — Shaping the Future Past — 49

Chinese and world history." 75 Talking of the place of the immigrant and how we tell their histories within our own, historian Donna Gabaccia writes of how the human story does not fall neatly into "nations and national categories," and that we must be students of "several nations, and of the ethnic, religious and regional loyalties that sustain-and sometimes motivate--migration."76 Many other historians, too, have documented the need to explore how people move around and through the various nation states as an essential part of understanding any one national history. It would be impossible to understand Kwan, and to place her properly within the context of her own history as a woman, a scientist, and a Chinese-American citizen, without understanding this earlier half of her life.

In specific categories of interest, most Chinese immigrants to the United States prior to $20^{\text {th }}$ century were peasants, uneducated and poverty-stricken. By contrast, Kwan was one of 5,000 intellectuals and students stranded in the United States by the Maoist revolution. 77 Not only of a different social class, Kwan was also from a different time and era within China itself. Far from the ancient Empire steeped in tradition that most previous immigrants had left behind, Kwan was a citizen (not a subject) of a new nation, one that was attempting to redefine itself as modern rather than ancient and decaying, and one struggling to reassert itself as a world power-a vastly new and different

\footnotetext{
${ }^{75}$ Judy Yung, "Him Mark Lai: Reclaiming Chinese American History,” The Public Historian 25, no. 1 (January 1, 2003): 69.

${ }^{76}$ Donna Gabaccia, "Is Everywhere Nowhere? Nomads, Nations, and the Immigrant Paradigm of United States History," The Journal of American History. 86, no. 3 (1999): 1115, 1134.

${ }^{77}$ Ronald Takaki, Strangers from a Different Shore: a History of Asian Americans, Updated and rev. ed., 1. paperback ed. (Boston [u.a.]: Little Brown, 1998), 417; Him Lai, "I - Musings of a Chinese American Historian," Amerasia Journal. 26, no. 1 (2000): 3.
} 
Donnelly — Shaping the Future Past - 50

experience for the venerable epitome of East Asian civilization. Earlier Chinese immigrants often remained for years, whether working toward bringing families over from China or to continue to send money home. Kwan never intended to remain in the United States. Her intent was always to return to her county and help the process of transformation, ensuring the future prosperity of the modern Chinese nation. This unintentional immigration certainly informs her different experience of life in the United States.

Kwan also provides a counter experience-or, at least, a different experienceto what Haiming Liu has documented as the “Trans-Pacific Family” pattern of Chinese immigration into the United States. Conflicts and instability within China and the discriminatory environment in the United States interfered with the sense of community here that comes as a part of the normal attachment process that creates tightly knit immigrant enclaves. Rather than their ties to families back home being weakened and unraveled during the "chain migration" process, established and pre-existing kinship ties and family

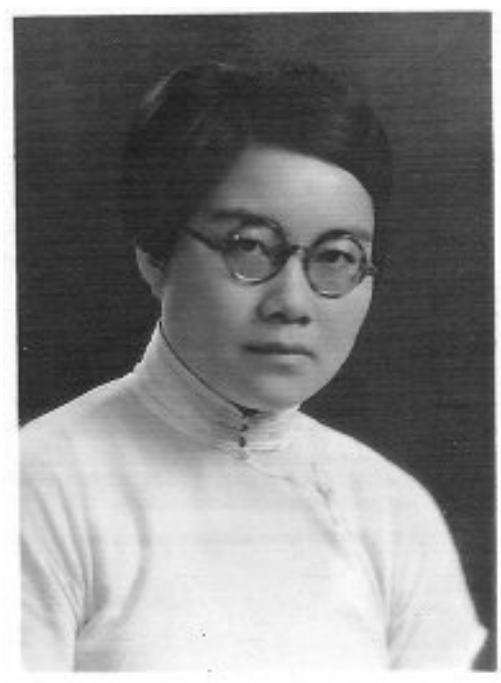

Figure 19 - Kwan Hsu, ca. 1932. This is very likely her graduation picture from the University of Shanghai. (Image from the Kwan Hsu Papers, courtesy PSU Archive.) in China became "the focal point of social existence."78 Kwan's family ties were disrupted, but she held on as best she could to what she did have, evidenced in

\footnotetext{
78 Haiming Liu, "Historical Connections Between the Chinese trans-Pacific Family and U.S.-China Relations," in The Expanding Roles of Chinese Americans in U.s.-China Relations: Transnational
} 
Donnelly — Shaping the Future Past — 51

part by letters to friends and cousins in Europe and the United States wherein she consistent enquires about friends and family "back home"- i.e., China. In light of the development of a modern "pan-Chinese" identity, Kwan's story provides yet another perspective.

Even though these records of Kwan's early years before she arrived in the U.S. are the least substantial grouping among her collected papers, there is plenty of material to put Kwan's early experiences in context, as has been shown in the previous pages. Her experiences as an outsider and a Christian are an integral part of the worlds of China and of occupied Shanghai, and at the same time provide a unique insight into that time. Research found no information in English sources about wartime scholarships for children, or how the schools kept going, or other details such as those found within Kwan's letters. This is not to say these records do not exist in other sources, most especially Chinese records. But as Henriot and Yeh observe, the breakout of the Chinese Civil War immediately after the close of World War II did not allow China the opportunity to put the war into any kind of complex perspective as most other nations did. The copious correspondence between Kwan and her fellow ex-patriots, and the memories of others that she has kept and recorded, all have the potential to provide personal insight into both the occupation of Shanghai and this particular Chinese diaspora of unintentional refugees stranded by Mao.

Networks and Trans-Pacific Interactions, ed. Peter Koehn and Yin, Xiao-huang (Armonk N.Y.: M.E. Sharpe, 2002), 15. 


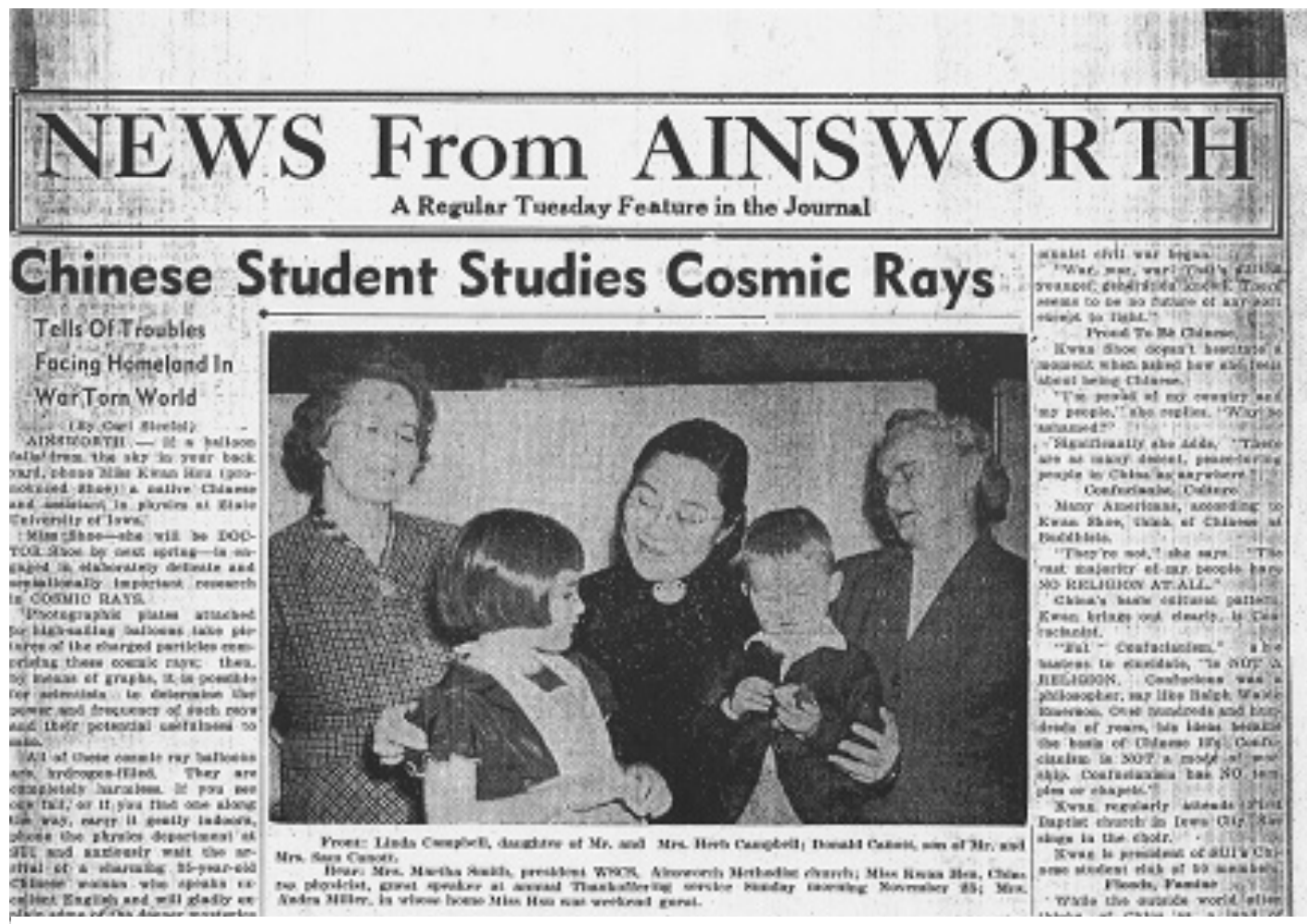

Figure 20 - This undated and unattributed article is from Kwan's personal papers, but was most likely written during her study at State University of Iowa. The image of her here, smiling serenely, is similar to other pictures from this same time period, and seem to indicate an attempt to paint Kwan as the stereotypical smiling, serene, exotic Asian woman. (Image from the Kwan Hsu Papers, courtesy PSU Archive.)

Kwan was 34 when she arrived in the United States to continue her education.

As a reward for her dedication during the war, Shanghai University, and the Baptist Missionary Board which oversaw its operations, had arranged a scholarship for Kwan's further study in the United States, with the understanding that she would return with her advanced education and teach at the University--

\footnotetext{
${ }^{79}$ Steedman, "Archives, Documentation, and Institutions of Social Memory," 7.
} 
Donnelly — Shaping the Future Past — 53

this was later amended to running their entire physics department. ${ }^{80}$ She also applied for and won an International Study grant from the American Association of University Women (AAUW). These grants were established by the AAUW as part of an effort to bring women from "liberated" counties to the United States to allow them to pursue further educational opportunities that were not available in war-torn Europe. Kwan was one of two women from China who were the first from outside of Europe to receive these awards. Here, Kwan's collection joins two historical subsets whose records are both slim and as yet understudied: Chinese scientists in the United States during the Cold War Era, and women in science.

Him Mark Lai, historian of Chinese-American history, delineated several areas of Chinese-American history that have yet to be fully studied. One of those areas is students who came from China to study in the United States. Lai identifies three waves, one in the early 1900s, one after World War II, and one in the 1960 s and 1970s, as relations between the two countries normalized. Kwan was part of that second wave arriving after World War II. He asks "What were the historical experiences of the three waves of students?...How were they affected by events in China and in the United States? What were their relations to the Chinese American community? To mainstream American society?"81 More importantly, perhaps, he asks, "What has been the historical experience of Chinese in academia? In engineering and the professions?"82 Kwan's archive,

\footnotetext{
${ }^{80}$ Carolyn Savage, “Looking West Toward China: The Life and Letters of Hsu Kwan,” Unpublished (Portland, OR, 1998), Portland State University Archives.

81 Lai, "I - Musings of a Chinese American Historian," 24.

82 Ibid., 25.
} 
Donnelly — Shaping the Future Past — 54

with its copious letters and diaries, as well as other papers and correspondence documenting, among other things, her various searches for a doctoral program, why she changed her major from Applied Physics to the then emerging field of Biophysics, and her quest for jobs over the years, is a rich resource directly related to the questions Dr. Lai raises.

There are other areas of investigation regarding Kwan's status as both Chinese and American. Dr. Zuoyue Wang of California State Polytechnic University, Pomona, is researching the history of Chinese American scientists during the Cold War. ${ }^{83}$ Kwan is one of the names on his list to investigate. ${ }^{84} \mathrm{He}$ laments that there has been little study on the lives of Chinese-American scientists and their role in U.S. China relations after Nixon reestablished ties. Kwan's life and her papers could yield insight in both these cases, as she was involved in both international studies programs that connected PSU with Chinese universities throughout her years in Oregon, and also a direct representative of the state of Oregon in promoting connections between businesses in Oregon with those in China. In one of his articles, Dr. Wang documents the nationalism expressed by many if not all of the students who were stranded here after the 1949 Revolution, most of them having come here, like Kwan, intending to return to China once

\footnotetext{
83 Wang, Zuoyue, "Zuoyue Wang Homepage," homepage, California State Polytechnic University, n.d., http://www.csupomona.edu/ zywang/.

84 Wang, Zuoyue, "Information on a Chinese-American Scientist - Klostes@gmail.com - Gmail", February 1, 2012, https://mail.google.com/mail/u/0/?ui=2\&view=btop\&ver=18zqbez0n5t35\&q=wang\&qs=true\&s earch=query\&th=1353d0865e2dc788\&qt=wang. $1 \&$ cvid $=1$.
} 
Donnelly — Shaping the Future Past — 55

their education was completed. ${ }^{85}$ Kwan's later years show that she, too, was one who, while she felt a connection to the land where she had spent the second half of her life, took pride in being able to explain the Chinese to the Americans and the Americans to the Chinese. Often, in her dealings with Americans in China, she found herself saying over and over again, "That's not how we Chinese do things."

Kwan was Chinese, and a scientist, but she was also a woman. Though archives were often written of as though they were a female lover by early modern historians, the contents of those archives largely ignored the stories of women. ${ }^{86}$ In the early twentieth century, the first women historians began to enter the field, even as it still largely ignored their contributions. This led to the tireless work of women like historian Mary Beard, who insisted that women had always been part of the construction of civilization; the records just needed to be found-and archives needed to make the effort so that the records could be found. ${ }^{87}$ However, despite their best efforts, the true establishment of the value of women's archives would have to wait until the advent of social history in the 1970s. However, even as women's archives grew and as identity-based archives came into being, a

85 Wang, Zuoyue, “Chinese American Scientists and U.S.-China Scientific Relations: From Richard Nixon to Wen Ho Lee," in The Expanding Roles of Chinese Americans in U.s.-China Relations: Transnational Networks and Trans-Pacific Interactions, ed. Peter Koehn and Yin, Xiao-huang (Armonk N.Y.: M.E. Sharpe, 2002), 207-234.

86 Bonnie Smith, The Gender of History Men, Women, and Historical Practice (Cambridge, Mass.:: Harvard University Press,, 2000), 116, http://hdl.handle.net/2027/heb.04359.0001.001. Historian Bonnie Smith documents a number of instances where Ranke and other early proponents of scientific historical enquiry refer to archives and their contents in gendered terms such as "fairy princesses" as well as referring to the misuse of archival materials as "rape."

${ }^{87}$ Anke Voss-Hubbard, "'No Document-No History': Mary Ritter Beard and the Early History of Women's Archives," The American Archivist 58, no. 1 (January 1, 1995): 17. 
Donnelly — Shaping the Future Past — 56

commitment to foster a greater diversity of voices did not mean that these focused collections were automatically more diverse. These archives sought to counter deliberate discrimination, but they could not compensate for factors such as lack of resources to obtain or keep collections, or the simple lack of material to be collected. In addition, because many women scientists labored in the trenches and were either denied credit or not allowed to spearhead major projects, a lack of "successful" names whose papers were considered to be of interest. ${ }^{88}$ However, Iowa State University launched a "Women in Science" archive twenty years ago; changing the traditional focus of archives (including women's archives) a bit in their statement of purpose, they sought to "document the experience of women in science-their roles, the professional challenges they face, and their private lives." 89 Note the lack of the word "success" or the requirement of any sort of renown in the description of this archive's function. What the Iowa State Archive has done is acknowledged a fact about much of women's history in general, but especially true of women in science in the mid$21^{\text {st }}$ century, that though they were "there in record numbers...one might have to look rather hard to find them."9o

So how and where does Kwan's story, specifically, make a useful contribution to either of these subsets? After her arrival in the United States in 1947, Kwan

\footnotetext{
88 Karen Mason, “Fostering Diversity in Archival Collections: The Iowa Women's Archives," Collection Management. 27, no. 2 (2002): 25.

89 Tanya Zanish-Belcher, "Documenting the Sometimes Invisible -- Working with Women Scientists," Humanities Collections 1, no. 4 (2001): 5.

${ }^{90}$ Margaret Rossiter, Women Scientists in America: Before Affirmative Action, 1940-1972 (Baltimore: Johns Hopkins University Press, 1995), xviii.
} 
Donnelly — Shaping the Future Past — 57

worked towards her Masters Degree in Physics at the University of Minnesota. When the United States withdrew all state personnel from the PRC early in 1950, Kwan shortly lost touch with all her family and friends back home. Forced to remain a student in order to maintain her visa and unable to plan for more than a few months ahead, she had to constantly search for that next sponsor, that next source of funding. As a foreign woman trapped in a nation struggling to come to grips with its own racist identity in a suddenly multi-chromatic globe, she had to negotiate for legal status with a government that could not decide if she was a potential troublemaker or a welcome guest.91 (It is to be remembered, too, that while the United States waged a Cold War against Russia and Eastern Europe, we dropped atomic bombs on Japan and fought all too real wars in Korea and Vietnam, among other non-European nations. ${ }^{22}$ Asia and her ancient cultures were far more alien than Russia or Germany even before the threat of Communism consumed much of the nation in the post-war years.)

In Kwan's papers are the letters and diary entries that document these years as a litany of refusals: she was denied employment and seen as "less qualified" than many less experienced, Caucasian candidates. One small woman's college offered her a position, but like many other women scientists, she feared "entombment" in such a college as a death knell for any hopes of establishing

91 Z. Wang, "Transnational Science During the Cold War," Isis 101 (2010): 371; Lauren, Paul Gordon, "Seen from the Outside: The International Perspective on America's Dilemma," in Window on Freedom: Race, Civil Rights, and Foreign Affairs, 1945-1988, ed. Brenda Plummer (Chapel Hill: University of North Carolina Press, 2003), 21-43.

92 Gerald Horne, "Race from Power: U. S. Foreign Policy and the General Crisis of White Supremacy," in Window on Freedom: Race, Civil Rights, and Foreign Affairs, 1945-1988, ed. Brenda Plummer (Chapel Hill: University of North Carolina Press, 2003), 46. 
Donnelly — Shaping the Future Past - 58

herself as a competent researcher in her field. ${ }^{93}$ Despite their often generous budgets for research in other areas, many all-women's colleges could not afford to maintain a physics department-or indeed, many of the hard science programsdue to the expense of equipment and the generally low enrollment figures. 94 Beyond employment, many universities simply refused to admit her as a student; here her gender as well as her nationality worked against her. In China, the possibility of a connection with her uncle's powerful family would have opened many doors for her; here she faced discrimination because of her gender, her Chinese nationality, and her Chinese education. 95

In 1953, the McCarran-Walter Act (also known as the Refugee Relief Act) created a new status for people like Kwan: permanent resident alien. Once her loyalty to the United States and her lack of communist convictions and connections were proved to the United States' government's satisfaction, Kwan was free to pursue her education. She was admitted to the University of California at Berkeley's physics program. Studying at a high-powered scientific research university, the same school where Dr. Chien-Siung Wu obtained her doctorate, Kwan found herself poorly prepared academically-a common problem with minority students who had not complete their undergraduate work at major

\footnotetext{
93 Rossiter, Women Scientists in America, 70.

94 Ibid., 211-212.

${ }^{95}$ Robert Burton, "The New Chinese in America," American University Field Staff Reports Service. East Asia Series (1966). 7, no. 8, East Asia Series (1966): 111-112. When they celebrated the $100^{\text {th }}$ anniversary of Huang Yanpei's birth in China in the late 1980s, Kwan was flown back to China and feted along with the rest of his extended family at the event. They still valued that connection.
} 
Donnelly — Shaping the Future Past — 59

United States universities. ${ }^{96}$ Yet more current research has shown that when matriculated into the biophysics program at Berkeley, Kwan would have entered a program that was in disarray, fighting for its academic life-and no one seemed to want to advise the graduate students. The definition of "biophysics" was still being debated amongst physicists and medical personnel; was it a field for medical doctors who knew some physics, or for physicists who had some understanding of medicine? At Berkeley, the applied sciences, with their established research budgets saw the discipline as a medical field-neatly laying the responsibility for funding its study on the medical school. The medical school did not agree, feeling that it would divert funding from their more traditional medical programs. Dr. Cornelius A. Tobias, a physicist himself, was brought in to run the department, and he wanted to stay in the applied sciences, not the least because of the access to Donner Labs and other state of the art equipment available to them, in addition to Navy and Army research contracts. 97 And underneath all of this is the experience of the students and others at the schoolstudents like Kwan, whose diaries and copious letters to friends during this time period could provide additional insight into this contentious time period at Berkeley.

\footnotetext{
96 Shirley Malcom, Hall, Paula Quick, and Brown, Janet Welsh, "The Double Bind : the Price of Being a Minority Woman in Science : Report of a Conference of Minority Women Scientists, Airlie House, Warrenton, Virginia, December 1975" (presented at the Conference of Minority Women Scientists, Washington D.C.: American Association for the Advancement of Science, 1976), 16.

97 Peter Westwick, “'Abraded from Several Corners:' Medical Physics and Biophysics at Berkeley," Historical Studies in the Physical and Biological Sciences: HSPS 27, no. 1 (1996): 151.
} 
Donnelly — Shaping the Future Past -60

Kwan documents her own experience as one of being so constantly called upon to see to the needs of other people, she at times failed to get her own research completed on schedule, creating uncertainty over her own future. Health problems plagued her, including depression. During these years she also turned down a marriage proposal from the brother of a childhood classmate; she would have had to leave her own studies behind to follow him to his own Ph.D. program in New York.

Kwan received her long-sought $\mathrm{PhD}$ from the University of California, Berkeley, in 1960. She was 47 years old. During her studies, she had worked as a graduate research assistant in nuclear medicine at the cutting-edge Donner Laboratory at Berkeley. She then obtained a position as assistant chief of biophysics at the Veterans Administration Hospital in Indianapolis and as an assistant professor of Biophysics at Indiana University. Like many qualified, educated women who worked in the sciences at this time, Kwan's name does not come up in a search of the written history of these facilities, nor is she mentioned in the transcribed oral histories of the men who ran those labs..${ }^{98}$ But her curriculum vitae reveals her involvement in the research. She is listed as coauthor of a number of papers on radiation effects on cells, publishing with both C.E. Tobias, professor of medical biophysics at Donner, and with her supervisor at the Indiana University School of Medicine, Dr. Leo Oliner. In her diaries, she recounts how she took care of the day-to-day minutia of the labs, covering other

\footnotetext{
${ }^{98}$ Lawrence, John, "Nuclear Medicine Pioneer and Director of Donner Laboratory, University of California, Berkeley: Oral History Transcript," interview by Hughes, Sally Smith,, 1980 1979, Internet Archive, http://www.archive.org/details/nuclearmedicine00lawrrich.
} 
Donnelly — Shaping the Future Past - 61

people's research while her own was neglected. Unlike in China, where her contributions had been accepted and rewarded, where she had powerful family connections, here she swept up behind the men who received the credit for the work done. "Blithely omitted as either unimportant or anomalous" is how science historian Margaret Rossiter describes the treatment women in science received in those years before Affirmative Action-an all too apt description of Kwan's experiences. 99

A report from a 1975 conference on the "Price of Being a Minority Woman in Science”, sponsored by the American Association for the Advancement of Science, reveals that Kwan's experiences were not atypical for a minority woman. While all women in the sciences struggled with the paternalistic and patronizing culture of scientists (a culture that has not changed much even today), for minority women the bind was doubled as both sexism and racism were the weapons employed against them. When quotas and outright biases could not keep women out of college programs, the attitudes and refusals of their peers to see them as equals and constant attempts to channel them into "traditionally feminized roles" served the same exclusionary purposes. ${ }^{100}$ Minority women, often like Kwan coming from traditional cultures with highly defined gender roles and lacking even the minimal social and cultural supports available to white women, were at an even greater disadvantage than their majority counterparts. In addition, Kwan was dealing with a different culture in a time long before any

\footnotetext{
99 Margaret Rossiter, Women Scientists in America: Before Affirmative Action, 1940-1972 (Baltimore: Johns Hopkins University Press, 1995), xvi.

100 Ibid., 57.
} 
Donnelly — Shaping the Future Past — 62

had thought to connect the words "sensitivity" and "training." At one point, Kwan's own sponsors and friends in the AAUW urged her to give up on her pursuit of the Ph.D. because she was "too sensitive and easily hurt to compete with men who are three times as strong as you are...though you have great ability, easily enough for the Ph.D." ${ }^{101}$ Not only was Kwan lacking mentors of her gender, her race, too, would have been an issue, and the lack of compatible mentors became more stark the further she advanced in the tiers of higher education. ${ }^{102}$

In Indiana in 1963, Kwan suffered a seizure and was hospitalized in the Hinsdale Sanatorium in Chicago. She spent several of the next months as a patient there, receiving a total of 48 electroshock treatments (EST) to combat depression and paranoia. Though they seemed to help at the time, these treatments led to memory loss, and Kwan feared for the rest of her life that she never gained back what she had lost. Twenty years later, her diaries record her continuing resentment that she had been given so many of what she felt were unjustified EST treatments. She told one cousin that she regretted ever agreeing to the treatments-perhaps one of the first and most devastating betrayals of the trust she had placed in both science and her religion to guide and inform her life. ${ }^{103}$

Finally, in 1964, with the help of her PhD advisor at UC Berkeley, Kwan obtained a permanent position at Portland State College (now PSU), becoming their first biophysics professor, charged with creating a sub-department and

\footnotetext{
${ }^{101}$ Savage, "Looking West Toward China: The Life and Letters of Hsu Kwan."

102 Malcom, Hall, Paula Quick, and Brown, Janet Welsh, “The Double Bind,” $1 ` 7$.

103 Huang, Tchang Fong, "Letter to Carolyn Savage”, October 15, 1997, Kwan Hsu Papers, PSU.
} 
Donnelly — Shaping the Future Past — 63

drawing in students to the new courses. When she arrived at Portland State, she became part of the largest group of minority women working in science education at the university level: Asian American women. Yet Kwan never "achieved" anything more than teaching for fourteen years and working on some research. How does her career fit into the histories of other women scientists, especially immigrant women?

Though their names are more well-known than Kwan's, a close reading of the lives of two other famous women physicists from this era, Dr. Chien-Shiung Wu and Dr. Fay Ajzenberg-Selove, shows that both women became famous due in large part or almost entirely to their work validating other people's data. Theirs was important work, influential work, but it was not original research. Kwan, on the other hand, did original research, including working in England in the early 1970 s to help develop porous membranes. Personal appearance and personality also factored into the careers of these two women. Dr. Ajzenberg-Selove discusses being "one of the boys," and "accounted as cute" by the men she worked with. Even in her days at Nanjing University, Chien-Shiung was seen as vivacious and outgoing, "known for her elegant manner."'“ Her initial entrance into Berkeley was at the request of the man who would become her husband, Dr. Luke Yuan. Leon Lidofsky, one of her first graduate students and a long-time friend, suggested that $\mathrm{Wu}$, Yuan, and Dr. Lawrence all knew she was accepted into the Berkeley program because Lawrence wanted to keep his graduate student, Yuan, 
Donnelly — Shaping the Future Past - 64

happy. ${ }^{104}$ Published histories of this time period include comments by Dr.

Lawrence and others about her "altogether decorative addition to any

laboratory."105 In short, part of Chien-Shiung's original entry and acceptance into the world of physics was because the men who allowed her in found her

appealingly soft and exotic. While some effort was made to cast Kwan in this

"exotic" light, as is evidenced by pictures taken during her early years in the U.S.,

Chien-Shiung was able to navigate within the stereotypical image of a "China

Doll" and benefited more than Kwan, who was stigmatized for her lack of

"pleasing mien." 106 Kwan was seen from her arrival as being somewhat

contentious and officious. And, though letters from friends, fellow students, and

her professors indicate she enjoyed working with the people around her, Kwan

never received the same level of sponsorship and acclamation that Chien-Shiung

enjoyed from the moment of her arrival in the United States. In fact, Dr. Zhu, in

his dissertation, compared Wu's career with others and found that male

physicists with a similar level of achievement were not rewarded or accorded the

104 Yuelin Zhu, “Chien-Shiung Wu: An Intellectual Biography” (Harvard University, 2001), 426.

105 Leon Lidofsky, “Chien-Shiung Wu, 29 May 1912. 16 February 1997," Proceedings of the American Philosophical Society 145, no. 1 (2001): 117-118.

106 Both women were referred as "Dragon Ladies" in their later years, when their careers were established. Students of both women complained about their unrealistic work expectations for their students, their demands in class, and their lack of approachability. Many of these issues can be attributed to the differences in the educational systems in the two countries and the two cultures. However difficult they may or may not have been to work with, as is often the case with strong women in a traditionally male field, Kwan and Chien-Shiung were more often denigrated than applauded for their strong personalities and determination. 
Donnelly — Shaping the Future Past — 65

same numbers of accolades as Dr. Wu. He concluded that she had been rewarded, in some senses, for being a woman in Physics. ${ }^{107}$

In the years 1942 to 1963 , UC Berkeley and UCLA had awarded a total of ten doctorates to women in "Physics and Meteorology," a staggering rate of one every two years. ${ }^{108}$ From 1947 - 1961, United States universities awarded over 6,000 total Doctorates in physics; of these only 115 went to women. Given these statistics, given the obstacles faced by women in general studying science in these years, and the additional obstacles of culture and alienation that Kwan faced, her achievement truly comes into focus. In spite of everything, she persevered, and she received her "almighty Ph.D." And, in an era when many universities were shedding women faculty and replacing them with men, or hiring qualified and educated women only to deny them tenure-track positions, Portland State hired a naturalized U.S. citizen whose first language was not English. ${ }^{109}$

107 Zhu, "Chien-Shiung Wu," 428.

108 Rossiter, Women Scientists in America, 86-87. I was unable to locate the total number of PhDs awarded in these subjects during these years.

${ }^{109}$ All the evidence points out that the favorable treatment Chien-Shiung had received ended once she obtained her degree. However impressive Lawrence found Dr. Wu, he did not offer her a position at Berkeley; and while he did pull strings to get her the job at Columbia, he did not put any pressure on his associates there to hire her as a tenured professor. 


\section{Donnelly — Shaping the Future Past — 66}

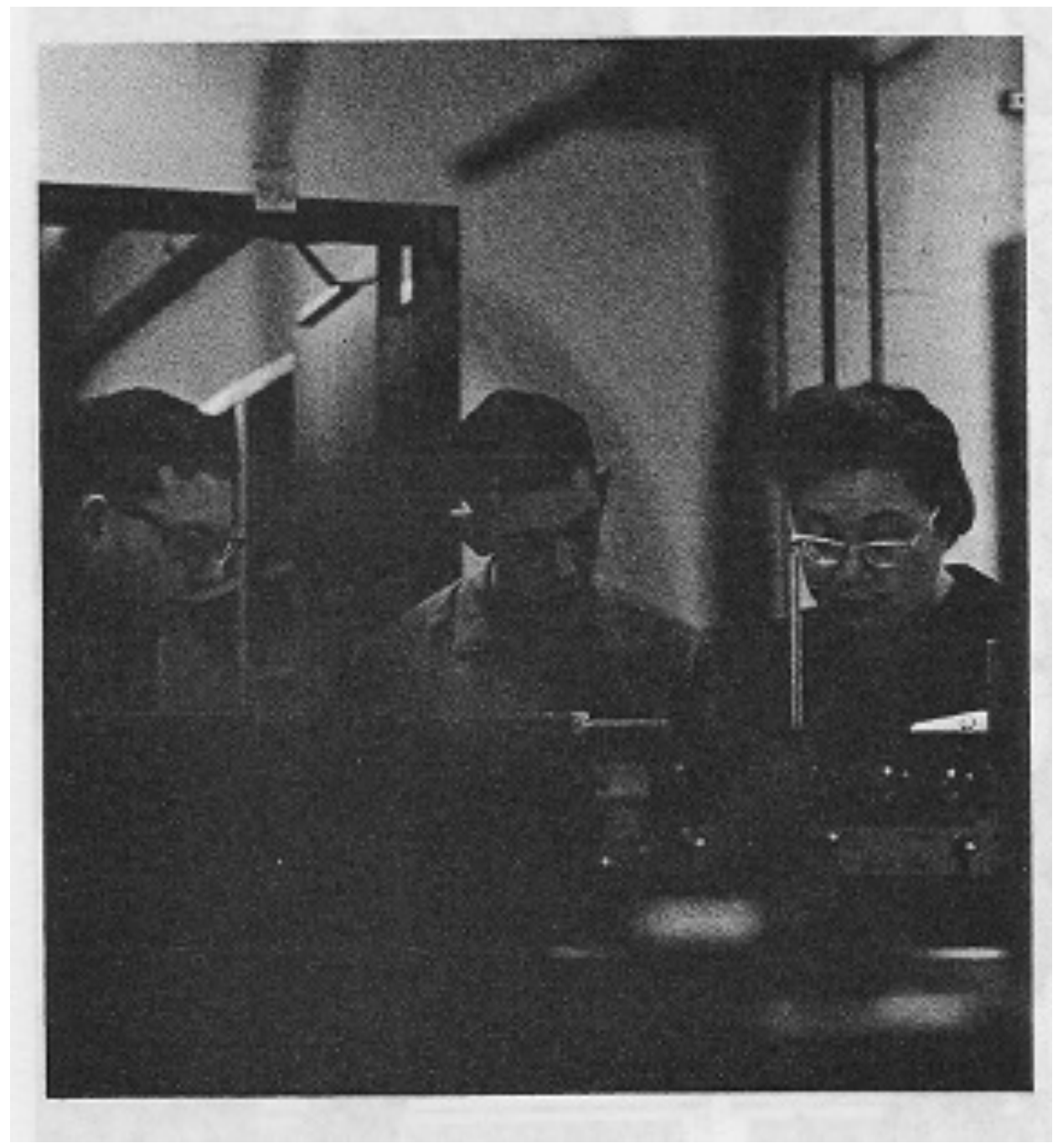

Figure 21 - Dr. Kwan Hsu instructing students at Portland State College. This picture was in the 1967-1968 catalogue. (Image courtesy Portland State University Archive.) 
Chapter Four: Re-MEMbering KWAN HSU

"The archival collection derives not from a conscious act of intellectual creation, as a book or article does, but rather from a gradual accretion resulting from activity over time."11o

Science in recent years has revealed a great deal about the physical components of memory, examining how our brains receive, store, and retrieve the data that creates any one memory. Identity, too, has become a hot topic, as the physiological components are revealed and studied. On the cultural front, in an increasingly global world some argue that we are becoming, in reaction, ever more insular, while most young people will tell you we are becoming more globalized and unified. Whichever way any particular individual leans, one thing that has been proven is that each individual person exists in multiple worlds at the same time. Family, professional, hobbyist, friend, acquaintance, and more, these are the identities we assume, the presentation of which will depend upon which group is present at any given time. Any collection of artifacts, documents, and other memorabilia will also need to represent that same multiplicity of persons-and in some ways, this is where a carefully processed collection can lead to a more full and valid historical interpretation by profiling and preserving the many facets, the various faces that an individual wore in their life, rather than the simplistic picture of a single-faceted person.

Yet, again, however accurate the representation, it is a processed representation, a facsimile filtered through the perceptions of those who shaped

${ }^{110}$ Society of American Archivists. and Fredric Miller, Arranging and Describing Archives and Manuscripts (Chicago: Society of American Archivists, 1990), 4. 
Donnelly — Shaping the Future Past - 68

the collection in its various stages until its accession into the archive-and it will be an interpreted archive in the end, no matter how non-biased the archivist has tried to be in the accessioning process. Throughout this project, events in and around Kwan's life were used to shape the archive and to explain how Kwan's story fits in to the need for the various historical archives in our nation. But however accurate the research, the end result remains a facsimile of Dr. Kwan Hsu. But that does not make it useless, far from it.

How is a history created that reflects a unique person, provides a unique perspective and is yet useful to the mainstream? It is not so great a task, perhaps, to document the path of a woman in a predominantly male world; this is not new ground after the thirty years of women's history-and women in history. What is new is Kwan's particular path through this world as a Chinese woman, an outsider in more ways than one. Also, in this case a Westerner is documenting a Chinese woman in a Western land. That cultural gap was hopefully accommodated by research and seeking understanding of the complexities and nuances her unique cultural background brings to the many facets of Kwan's life. But who is the woman whom the archive will represent? Other records will show that she was an exile, a foreigner in many ways in her own land as well as here. Mental illness was an issue in her life, one that left with fears of losing her mind and her memory. Kwan grew up in a culture that prized learning, and throughout her life she continued to live in worlds that were intellectual and text-based. In addition, her Christian belief and dogma were rooted in their various texts, from sacred books to their sermons and hymns and more. Kwan worked in a field that 
Donnelly — Shaping the Future Past — 69

relied upon received knowledge as much as it did theoretical research. Though not an archivist's stated goal, the choices made in the processing of personal papers will shape how any individual's identity is interpreted in the future. The question is how close can that reflection come to being that of the real person?

Honor Sachs, in her article "Reconstructing a Life: The Archival Challenges of Women's History," details the generally accepted image of a woman in Colonial America named Annie Christian. Ms. Christian was Thomas Paine's sister, and she married and followed her husband to settle in Kentucky, where he died not long after their arrival. The accepted historical image of Annie was based largely on letters now housed in the Virginia Historical Society's collection, a correspondence that took place between Annie and two particularly close friends and confidants. These letters paint a picture of "a beleaguered, dependent victim of a zealous husband's decision to move west." ${ }^{111}$ However, in the late 1990s, a new collection of papers was made public, and an entirely different picture of the woman came to light. Kept as part of a family archive that had passed down through the Christian family for years, these documents included a great deal of invoices, letters, and notes that showed Annie dealing with both the family businesses and the day-to-day life in her home. This Annie Christian "little resemble[d] the financially helpless, emotionally exhausted woman" that had been the accepted portrait of her throughout history. ${ }^{112}$

\footnotetext{
${ }^{111}$ Honor Sachs, "Reconstructing a Life: The Archival Challenges of Women's History," Library Trends 56, no. 3 (February 14, 2008): 655.

${ }^{112}$ Ibid., 659.
} 
Donnelly — Shaping the Future Past — 70

Ultimately, what Sachs discovered was just how this one woman's identity through time had been shaped by the decisions of the various archivists involved and their interests in her collected papers. For some, Annie was just a side-note to her more famous brother and other acquaintances, more interesting because of her relationships with them than for anything inherent in her own life. Similarly, in Kwan's life, there are those who would see value only in her familial relationship to the Huang Yanpei family, and even more peripherally, the successful Chinese-American author, Amy Tan. But, like Annie Christian's legacy, for others Kwan's was a family story, important for their connections with her and their memories. Chief among these people was the woman who donated her collection to the PSU archive, her friend, Carolyn Savage. Both of these frameworks have their value, but neither is complete in and of themselves. Given this irreconcilable divide between these two approaches, Sachs concludes we can't really "know" anything about Ms. Christian's life beyond these brief snapshots in time. But she insists what is truly important in Annie's story is that historians understand the way a collection and how it is preserved, processed, and handed down through time can shape the memory of a person. ${ }^{113}$

Wearing masks is part of being human. Investigations into an archive may find more than one "person" there, depending on the way in which the information available is assembled-and what information was available in the

113 I would argue that these different faces of Annie Christian represent the many faces women wear throughout their lives. More so than men, women have worn many hats, and often operated in vastly different venues. So I do not think it is so much an "unknowable" person, as an acceptance of the multi-faceted person that we are dealing with, and that Annie Christian was both these people, andmore. 
Donnelly — Shaping the Future Past — 71

first place. Any individual's history, then, is created by the arrangement of these various building blocks-and the woman Kwan Hsu in this PSU collection will not necessarily be the woman who her closest friends knew, or the woman her brother knew, or the woman, even, that her coworkers and colleagues knew.

Like Annie Christian, the Kwan represented in this collection will be both more and less herself. Less, because the collection represents only a part of the entire woman, but more, because she is no longer only one person; she has become a representative example of the various groups to which she belongs. She is compartmentalized, one Chinese woman among others, one exile and immigrant in a group of immigrants-and yet she is a unique example of each of these subsets. To properly represent her past to the future, this collection should reflect these things and provide as much information as it can on those aspects of her as a person. But, ultimately, the identity, the memory of Kwan will be one that is created by this collection of papers and ephemera, which will then become part of the larger archive at PSU and, ultimately, the historical record of Kwan's times and places.

But how is that record created? Methods of archival appraisal have come to the fore in this era of social history and exploding record creation. Besieged by burgeoning records and materials considered essential to the knowledge of future historians, what kinds of guidelines and standards are used to determine what is kept and what is not? As discussed earlier, the National Archives of Canada laid out a method when they called for archivists to, among other things, "deliberately 
Donnelly — Shaping the Future Past — 72

give voice to the marginalized, the losers."114 But beyond Kwan's historic identity, the collection has to be accessed in order to be useful-and not just because of the modern constraints generated by concerns with budgets, space, and competing interests. On a more fundamental level it could be argued that if the public never accesses or learns from the accumulated and archived material record of their past, they are effectively separated from their own heritage. ${ }^{115}$ But while an archival collection is an assembly of historical evidence, is it truly part of the historical record? To make it so, someone needs to come through and add interpretation and shaping, more so than is done just in the collection's assembly. Records need to become part of the people's story. ${ }^{116}$ Yet how is the selection, culling, and sorting decided for this collection that is the ephemera of a life? How is what could be useful now to be judged against what will be useful in the future-and what, over all, is the purpose of this archive and the history it could and will tell?

Mircea Eliade, a religious history scholar of some renown, wrote that in the pre-Enlightenment European world, "history could be tolerated because it was necessary," necessary to record the highs and lows and destructive phases of life because, in the end, history would bear witness to the necessity of the universe resetting itself, renewing the world and beginning the cycle of life over again."

\footnotetext{
114 Cook, "Remembering the Future: Appraisal of Records and the Role of Archives in Constructing Social Memory," 174.

115 Wilson, Ian E., "The Real Thing for the Pepsi Generation," in Archives, Documentation, and Institutions of Social Memory: Essays from the Sawyer Seminar, ed. Francis Blouin and William G. Rosenberg (Ann Arbor: University of Michigan Press, 2006), 339.

116 Ibid., 333.
} 
Donnelly — Shaping the Future Past — 73

History had meaning, therefore, in its connection with the eternal cycles of life, how it connected this year with the past year, this ruler with a past ruler, this celebration or ritual with the ones in the past. Even after Christianity forced its teleological imperative over all of history, many European peasants and even some educated people still believed in this cyclical use of history. Enlightenment notions of "progress" and modern scientific history came along and pushed the cycles further back in the public consciousness, but that belief is not gone. Enlightened modernity may smile when Elton John sings about the "endless round" and an "unfolding path" in the "Circle of Life," but in truth, this was how most people understood history in the past, in cycles and seasons. ${ }^{117}$ More recently, historians David Thelen and Roy Rosenzweig documented a similar viewpoint in modern audiences for history.

In Rosenzweig and Thelen's study, conducted in the 1990s, they found that public uses of history, as opposed to academic or professional, often stemmed from a sense of the patterns and repetitions in a personal or family history. Newer generations gradually aged and replaced older generations, creating "cycles and circles" in the histories of individuals and families. ${ }^{118}$ While there is much to be written about the difference between academic history, which is distinctly linear, and this view of more personal history, or heritage, this indicates that just because modern knowledge and learning has said, "history moves in a

117 Rice, Tim, “The Lion King Lyrics - 'Circle of Life'”, n.d., http://www.lionking.org/lyrics/OMPS/Circle-EJ.html.

118 Roy Rosenzweig and David Thelen, The Presence of the Past (Columbia University Press, 2000), 68. 
Donnelly — Shaping the Future Past — 74

straight line" does not mean that modern people have lost their affinity for viewing the passage of the future into the present into the past as something other than cyclical. Time, after all, is not a constant in physics; light is. Time bends and shapes itself around gravitational wells and planets; it can be outrun by anything fast enough and pulled in different directions. Many non-Western cultures still hold notions of time which are distinctly non-linear, challenging and forcing us to reexamine our own notions of purely linear time and history. Historian Richard Evans gives what he believes is a rather thorough rebuke to this notion of non-linear time, citing the fact that "everyone" likes a novel that proceeds linearly. ${ }^{119}$ But he is guilty of assuming that everyone prefers a Western mode of story-telling. If he read novels by well-known Native American writers such as Sherman Alexie or Louise Erdrich, he would find himself in a distinctly circular story-telling mode. It is the same with some Asian films and stories-the film "Hero", for instance, in which the narrative continually turns in upon itself before the final denouement. Additionally there are the cycles of African tales, and the way that epic histories throughout time in Central Asia reflect similar cultural elements, necessary for "great person" status, but are also rooted in this circular, cyclical notion of history and story-telling.

Western civilization and the historians trained in that tradition also continue to equate "historical consciousness" with that sense of a linear motion of time, and further, assume that our concept of time is the correct definition, as if history

\footnotetext{
${ }^{119}$ Evans, In Defense of History, 121-122. Or perhaps he is merely unaware that he is flashing his "white male privilege" card.
} 
Donnelly — Shaping the Future Past — 75

that is told in Central Eurasian epics and the songs of the African griot is not history. Homer was both history and epic tale; most historians accept that as fact. The epic and the song are not Western history, nor are they based on our definition of scientific research, but they are history rooted in their own native concepts of time and tradition, with their own methods of validating that history. The Western sense of history is rooted firmly in the idea of a forward progression of time-but there is no certainty this will be the way in which history is told forever. ${ }^{120}$ The forward progression of time as an aspect of scientific history makes the most sense today, in this place and in this time. But will it still make sense tomorrow, or a hundred tomorrows from now? Appleby, Hunt, and Jacob document the impact in the 1960s and 1970s of the many minority and female students on the field of history, how they brought in with them different ways of knowing and different ideas about the truthfulness of time and history for any large group. These historians of different cultures, colors, and genders helped to launch the social history movement. ${ }^{121}$ Post-modernism, too, shattered traditional Western approaches to history and belief in the sanctity of written knowledge, let alone historical knowledge its roots in the validity of archives even as it enlarged boundaries and generated an ability to examine evidence for the different stories it could tell. ${ }^{122}$ Both of these movements, as well as others in the past, have changed history as it was known into something that many earlier

\footnotetext{
${ }^{120}$ Appleby, Hunt, and Jacob, Telling the Truth About History, 59.

121 Ibid., 146-147.

122 Evans, In Defense of History, 216. Though he is hardly the only one making this argument about the effect Post-modernism has had on current methods of historiography.
} 
Donnelly — Shaping the Future Past — 76

historians weren't even always convinced should be called history. Yet the historical narrative is enriched by this wider, more complex story, even as historians and the public argue and squabble over the changes this has wrought in the national narrative and its structural supports within the culture of the modern United States.

What does all this have to do with the papers of Kwan Hsu? Cycles and circles and various means of knowing? If historiography, like time, is not a constant, there is no way to know what future historians will need or find valuable in this collection. It is not possible to make decisions based upon how these historians will root their future in Kwan's past, or how they will use her history. This particular argument, the unknowable shape of future historiography, was initially a riposte to the assertion that Kwan's papers were not interesting "enough"justification for keeping everything. Nothing can go because what will be needed in the future cannot be determined. As the collection was surveyed and studied, that assertion became, instead, a burden, leading to fretting and fears of disposing however inadvertently of the wrong piece of information, the wrong receipt that would be absolutely necessary to any future historian. Fear paralyzed the decision making process.

Two facts stood out at this point: Records exist in the future as something they were not necessarily originally created to be, and history, as it is currently practiced, is a relatively new invention in the annals of civilization, whether nomadic or sedentary. Given the cyclical nature of public memory, and the inability to know what changes the future will bring, decisions cannot be based 
Donnelly — Shaping the Future Past — 77

upon concerns about how future archivists will make use of this collection. But for that very same reason-that time is fluid and not a fixed point in the universal continuum-there can also be no assumptions that there will not be some "mediating [of] competitive and shifting notions of value" in the future. ${ }^{123}$ Objectivity and critical assessment and appraisal are necessarily of their time, and if that is all they are, they will still be of use in the future for that reason alone. Terry Cook warned that "Setting appraisal or memory values based on past, present, or anticipated historical research use patterns is fraught with conceptual and practical problems...appraisal, for all its subjectivity, requires a defendable intellectual framework." This would be accomplished, he believes, by archivists "[making] widely known their appraisal choices, the reasons for them, and the research documentation supporting those choices.”124

Putting it another way, it has never been the archivist's job to "provide a finding aid that is responsive to all of the questions of all of their users all of the time." 125 Or (and more succinctly) as Dr. Lang once said, "Leave something for the researchers to do for themselves.”

As history and culture cycle through time, this small material record of some of Kwan's life will possibly hold or even gain meaning in the future. Neither hope nor chance can be denied, and that, too, contributes to the value of this collection. Historians cannot worry about controlling either the past or the present in order

\footnotetext{
123 Blouin and Rosenberg, Processing the Past, 153.

124 Cook, "Remembering the Future: Appraisal of Records and the Role of Archives in Constructing Social Memory," 178.

125 Blouin and Rosenberg, Processing the Past, 211.
} 
Donnelly — Shaping the Future Past — 78

to hold or create value for the future. This collection can represent the woman in history and the archivists in the present and still have value to the future past. Cycles lend records value, because, as in times past, they create the history which roots both the self and the present in time and space. This is the meaning, too, of archives: keeping the records of events and people, returning to that root of archival documents and memories as representative of something worth recording, worth re-membering as part of a narrative. Numbers as well as events and people eventually become sacred parts of explanatory narratives. ${ }^{126}$ These public forms of memory, or folk memory, do not always match up with the material evidence of history, whether that of Kammen's "plasticized apotheosis" or something more vibrant. Academic history, with its scientific inquiry works with the records more exclusively, focused less on memorial and more on factual inquiry and interpretation. Public historians work to bridge the gaps that can develop between the cyclical creations of heritage favored by the general public and the stricter, linear histories of academic historical consciousness.

Then, too, a desire to control the information that future researchers would find about Kwan also had a far less esoteric component: it was, simply, an issue of control. It can be a protective response, growing from affection generated by knowledge and familiarity with the individual-much like what is seen in Carolyn Savage's own manuscript about Kwan. Determined that the world would know and understand what a remarkable woman her friend was, Ms. Savage sorted and selected through Kwan's papers to assemble her own manuscript detailing

126 Linenthal, History Wars, 79. 
Kwan's life. In the end, her manuscript presented an image of Kwan that author Amy Tan described as "far more personal than what might intrigue an ordinary reader.” Though Kwan's story was remarkable, such a controlled and personal vision of her was not, in Ms. Tan's professional opinion, truly publishable. ${ }^{127}$

Though perhaps not consciously protective, Ms. Savage's depiction of Kwan preserved and held up for public perusal the person that she knew-a natural response, one that can be expected of any person tasked with sorting through and appraising a collection. It is also a response that even today overrides freedom of information and the rights of the public in favor of the private. Why else

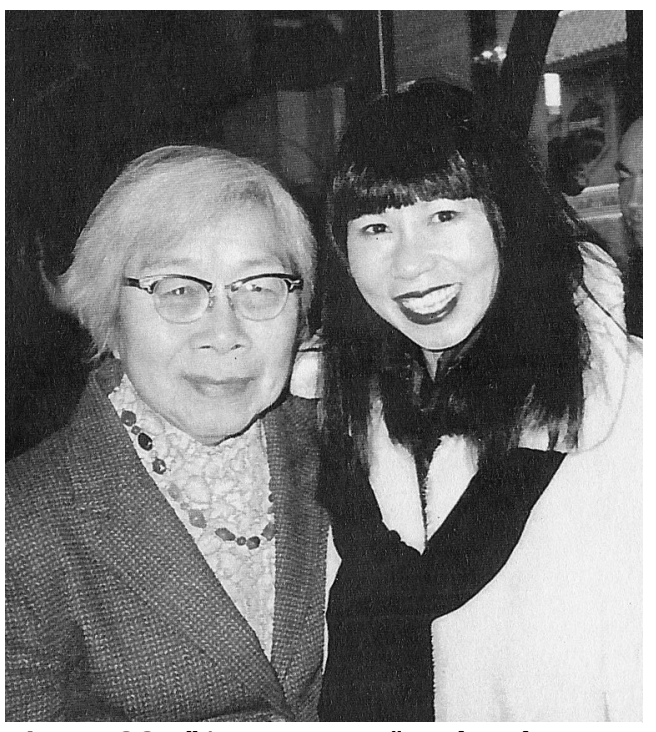

Figure 22 - "Auntie Kwan" and author Amy Tan, ca. 1990. (Image courtesy Portland State Archive.) would politicians and other public figures seal their personal records for years after their deaths? On a more prosaic level, when appraising any collection some documents and artifacts could appear to have more value than others, and there is a nearly instinctual desire to be certain that future researchers could find these and interpret them "correctly." Here especially is where the historian's need to analyze, assess, and interpret conflicts directly with the archivist's craft of appraisal. An archivist is responsible not to tell a story, but to assemble Portland State University Archive. 


$$
\text { Donnelly — Shaping the Future Past — } 80
$$

information, judging its worth and value as records and as evidence of Kwan's interactions with the worlds in which she moved. It is up to later historians and other inquiries to interpret the records as they find them. 
CHAPTER FIVE: EENY-MEENY-MINY-MO...

"Appraisal imposes a heavy social responsibility on archivists. As they appraise records, they are doing nothing less than shaping the future of our documentary heritage." 128

As history and archives struggle to fill the gaps in our national and international narratives, Kwan could have been pigeon-holed into any number of categories. Was she to be identified as a woman first, or as Chinese, or as a scientist? Were qualities of ethnicity and gender the most important ways to identify her, or was there another way? How could I best assemble these materials to reflect what I found to be of value, or, more importantly, what was Kwan's sense of herself and her history? Was there any way to truly incorporate her vision of herself into the collection? In my forays through the archives, I became convinced, ultimately, that Kwan saw herself a Chinese American first, and a scientist second. If I had come upon her papers earlier in her life, that may very well have been a different order-or an entirely different category. What about her religion? Reading through her various letters and diaries, Christianity seemed even more than science to be her window into United States' culture; it is where she found her identity away from the lab and the classroom. But when dealing with these other issues, Christianity took a back seat to her other “identities." In fact, it often seemed that her religion was part and parcel of her relationship with Shanghai University, and only after she came to the United States was it more removed from her educational experience in general. Then

\footnotetext{
${ }^{128}$ Cook, "Remembering the Future: Appraisal of Records and the Role of Archives in Constructing Social Memory," 169.
} 
again, Christianity is one means of gaining tools to deal with life and with the problems life can throw at you, and for many years in the United States, Kwan's education dominated her life.

A good example of this is found in a letter from Kwan to her friends and family in the United States, written while Kwan was a visiting professor at Shanghai Institute of Mechanical Engineering (SIME). Writing to a fellow graduate of the University of Shanghai who was also a professor in the United States, she said, "My position here is quite unique. [An American friend] told the people here that I am very American; and the people here told her that I am very Chinese. To me, it is indeed a compliment. Americans do things the American way, and the Chinese do things the Chinese ways."129 In other letters from this time period, she details how she interprets both culture

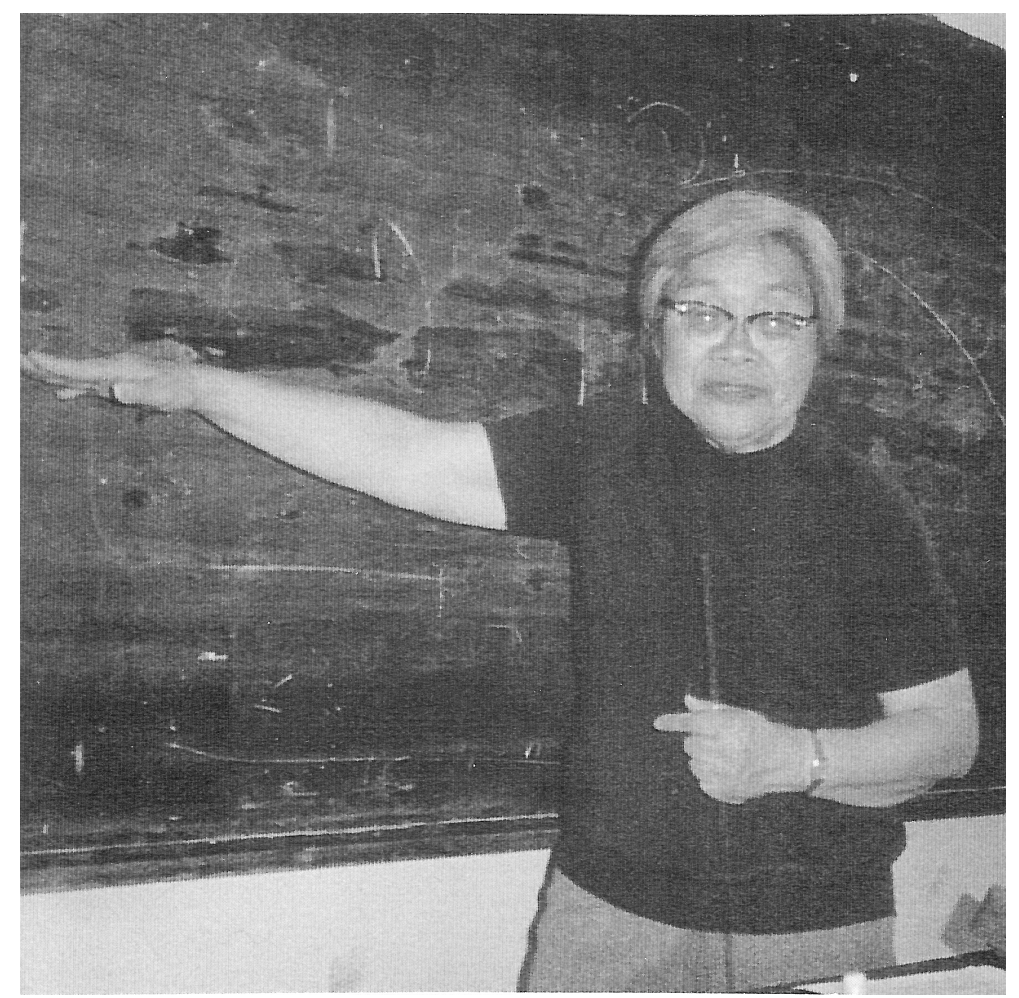

Figure 23 - Kwan Hsu, teaching at Shanghai Institute of Mechanical Engineering in the summer of 1986. (Image courtesy Portland State Archive.)

${ }^{129}$ Kwan Hsu, "Letter to C. K. Zhang”, March 14, 1986, Kwan Hsu Papers, Portland State University Archives. 
Donnelly — Shaping the Future Past - 83

and language for non-Chinese, mostly European acquaintances when in China, and often comments to the effect that "They don't understand how we Chinese do things."

The final issue that needed to be addressed was the dismantling and reordering of Kwan's papers before they came to the PSU Archive. Ms. Savage put a great deal of time and effort into organizing Kwan's papers. Much of her organization made sense, such as grouping documents related to school in one area, and personal correspondence sorted and organized according to recipient. But in addition to the note found which indicated Kwan had assembled a collection of letters that related to her mental illness, I found another note that read, "these letters are from Viola, Peter, proposal letter. They are precious." Again, these letters had been separated from this original grouping and parsed out amongst the larger collection, now impossible to locate. In some ways, Ms. Savage's assembly made the archive easier to process, but on the other hand, the value of that personal assembly, that original "fond" of letters is incalculableand irretrievable. Additionally, as I worked my way through the archive, the chronological order did not hold up. Events that seemed connected by time were separated by those involved and by the arena of involvement. School or church? Home or travelling for Huanjing Academy? Materials that were important to Ms. Savage's own manuscript of Kwan's life had been set aside into a "primary" collection of sorts. One fortunate find was a manila file folder bearing a note indicating that all the papers within had been contained in a notebook marked "immigration." Further work in the collection led me to believe that in her later 


$$
\text { Donnelly — Shaping the Future Past — } 84
$$

years, Kwan had simply organized every piece of mail she received in date order, then hole-punched them and put them away with the year neatly labeled on the folder.

Ultimately, the assessment rule was threefold: What does this particular record or artifact reveal about Kwan as a person, a Chinese-American woman, and a scientist? Where this problem was demonstrated most vividly was the number of letters detailing her ongoing battles with various subscription services over the cost of books bought and payments made and not credited, where she is, quite literally, arguing about pennies. On one hand, it's potential evidence that she had lived with want and in need, and she was in a field that was all about minute detail, where small things mattered. It reveals her character to anyone who cares to look in the future. On the other, the number of these and the other, somewhat petty disagreements that show up in her papers do not cast Kwan in the best light. If in the future she is to be taken seriously as a scientist and a representative of her many groups, should these sorts of records be left in with her serious research and her diary entries about mental illness? (Not to mention that the word "petty" is in and of itself a judgement of the evidence.) This kind of obsession with detail is part and parcel of being a scientist; should we wonder that this shows up elsewhere in her life? And if it did show up in other areas of her life, were those records, perhaps, better illustrations than these letters? Ultimately, that was my conclusion. Though admittedly thinking more as a historian than an archivist, I determined that there were other areas within the collection that better demonstrated this aspect of Kwan's personality, and these 
Donnelly — Shaping the Future Past -85

"petty" records could safely be culled. With the actual physical space the collection takes up being a concern, it was a legitimate call to keep what were felt to be the best demonstrations of Kwan's life and character.

On the initial pass through, three series were tentatively assigned to the collection: Education, Personal, and Professional. Pictures and Carolyn Savage's contributions to the collection were added as individual series later. For the pictures, it was determined there was not going to be a way to identify all the images as to time and place taken, or people. As to the final disposition of Carolyn Savage's contributions, more thought was required.

Some of the easiest decisions were for items like a box of old diskettes, $3^{1 / 4}$ and 5 1/2 floppies. Only the "hard" body diskettes were accessible, and once it was determined that the material on those was already in the collection in hardcopy, the diskettes were disposed of. The fact that they were already near-inaccessible technology also contributed to the decision. The collection of business cards from various Chinese companies and businessmen was another "easy" decision to discard, since there was no way to tie Kwan specifically to any of these companies. Newspapers, magazines, old calendars, and books were also removed from the collection, albeit with a list of the books included in the finding aid. Most of Kwan's personal and professional correspondence was retained, with the exceptions of the many book orders she'd made, book clubs to which she belonged, and so on. While these letters do lend themselves to the interpretation of her character as a scientist and perhaps her mindset as she aged, that information could be determined by other, better means. Again, lists were made 
Donnelly — Shaping the Future Past — 86

of the information, possibly to be included in the final finding aid for the collection.

Personal records were evaluated on a case-by-case basis. Credit cards were removed, as were social security cards and driver's license; ID cards for professional and other groups were kept. Letters complaining about misinformation on food labels were kept, because they were interactive and again reflected Kwan's life as a scientist. Medical bills and insurance papers from her later years were removed, as the information contained in them is highly personal and Kwan's death was less than twenty-five years ago. However, personal studies of blood sugar and how certain medications affected her physically were retained. These were meticulous, rigorous scientific studies, and demonstrated Kwan's scientific persona in her life beyond school and lab quite well.

For her professional series, Kwan's various CVs and resumes indicate to what professional groups she belonged and most of the affiliated newsletters had no direct relation to her. In addition, most are archived elsewhere, generally by the organization itself. Travel vouchers and other receipts were largely thrown out, too, but programs for the various conferences she attended were retained as a record of her attendance. The travel costs were considered to be nonessential as that kind of information was available in other formats for this time period. Kwan was one of the organizers of a Radiology Society conference in Portland. These materials were, in the end, mostly disposed of, as most of what Kwan seemed to do was simply organize the venue. Material with her name and directly relating to those efforts was kept. This held true for all her other professional organizations 
Donnelly — Shaping the Future Past - 87

and educational activities, including her association with the AAUW and the Baptist Foreign Mission Board. Kwan was active as an alumni of Huajiang Academy (the wartime name of Shanghai University) and also active in the International Studies program at PSU. Anything directly and at times peripherally relating to Kwan's work in these areas was kept.

Correspondence with colleagues and students was retained, as were the day-to-day records of her work and her life as a professor and as a researcher. The personal correspondence that had been so assiduously separated out by Ms. Savage was left as she had organized it. Resorting the material would have taken a great amount of time, and the dates on the letters will help with matching individual times and places with other events in Kwan's life. Also, Carolyn Savage had conducted a great deal of correspondence with a number of the various people in Kwan's circles of family, friends, and acquaintances, and these letters were originally included in the corresponding folder. After much thought, these materials were separated and placed into the series with the rest of Carolyn's material. While they do give insight into Kwan, her past, and her relationships, they were not authored by Kwan herself. Nor were they sent to Kwan, as most of them were written after her death. For clarity in the future, it seemed best to place all of Carolyn's contributions to the collection in her own series, so that authorship would not be confused and interpretations of Kwan herself could be freer.

Kwan's papers contain a considerable amount of untranslated Chinese materials. Most of this was left in situ, in a series of its own. It is hoped that in the 
Donnelly — Shaping the Future Past — 88

future, a Capstone project or an advanced Chinese class will take on the translation of at least some of this material. However, at this time I do not have the language skills necessary to make judgments on these, and as they may have insight into the trans-national aspect of Kwan's identities, anything that was handwritten was kept. Magazines that Kwan acquired after the normalization of relationships between the United States and the P.R.C. were not kept, as most of those were tourist type magazines, though, they, too were documented as to their presence in the original collection. Items that dated before the reestablishment of diplomatic ties between the two nations were kept. A number of the personal Chinese and other non-English letters had been separated out and translated at the behest of Carolyn Savage. These letters were placed together with any translation in the folders with other, similar material (such as other letters addressed to the same person) where it was possible, but where it was not, they were placed back in with the rest of the untranslated materials.

Finally, the Carolyn Savage materials were assembled into their own series. Biographical material which she assembled was pulled from the collection, as were her notes and other comment. Where possible, their position was recorded, but as I worked through the collection, I felt that leaving Carolyn's notes and comments in the collection was not only potentially confusing, but possibly veered too far over into interpretation. Ms. Savage had a definite picture of her friend she wished shaped out of this collection, and while I understand that struggle, as I have dealt with it myself, I have also tried to step back and be 


$$
\text { Donnelly — Shaping the Future Past — } 89
$$

transparent about this. Ultimately, the goal is to let the assembled material speak for itself, rather than offering interpretations on a case by case basis.

There were other decisions, but much of the nitty-gritty is visible in the Finding Aid, and it seems redundant to continue with "this was left in, this was left out." The selections elucidated here will hopefully provided an expanded scope for the general information in that document, and perhaps the next time a graduate student goes fishing for something written on "how to process a collection," this will turn up as a case study. 


\title{
CHAPTER SiX: CONCLUSIONS?
}

\begin{abstract}
"The grammatical tense of the archive is not, then, the future perfect, not the conventional past historic of English-speaking historians, nor even the passee historique of the French, but is instead the syntax of the fairy-tale: "once, there was," "in the summer of 1751," "once upon a time." 130
\end{abstract}

Settled in Portland after 1964, Kwan's life seemed to have come full circle. She held a teaching position again and part of a research university. She took a year's sabbatical to work on a special research project in England. Kwan received tenure, teaching graduate and undergraduate classes until her retirement in 1978 at PSU. She continued to be active at PSU for a number of years as an emeritus professor. Together with two other professors in the department, Kwan researched lipid membranes, and contributed to studies which advanced her field of biophysics. However, she found herself a poor fit with the local Chinese community; in one letter she wrote of how uncomfortable going to one of Portland's traditionally Chinese Baptist churches made her, and she felt more comfortable in the Anglo Baptist church. Yet there, too, she was an outsider, but she did not want to simply go to the Chinese service because it was expected of her. This prompted her to write to a friend, "Social problem is more difficult than physics problem."

When Nixon reestablished ties with China, Kwan happily resumed contact with family, friends, and colleagues from her former university, now Shanghai Institute of Mechanical Engineering (SIME). At the first opportunity, she

\footnotetext{
${ }^{130}$ Steedman, "Archives, Documentation, and Institutions of Social Memory," 14.
} 
Donnelly — Shaping the Future Past — 91

obtained a visa (Canadian) to return to Shanghai and visit with her younger brother and stepmother. Kwan lead many tours of PSU students and professors to China, attended events the PRC held in honor of Huang Yanpei's 100 ${ }^{\text {th }}$ birthday, and actively worked to promote cross-cultural understanding between the communities, and to connect academics in both countries with one another. If "biography is the intersection of culture and individual,"131 then Kwan's biography is a unique creature. She belonged to several different worlds, several different groups-and yet, she did not belong to any of them fully except, perhaps, the community at the University of Shanghai. But she did not live her entire life in any one bubble, and there is danger, too, in creating a collection that is too exclusive, of becoming so focused on the uniqueness of this material that both the evidence and the person are separated from any context which makes it useful outside of the narrow lens of one individual life.

Kate Theimer (@ArchivestNext), an archivist and writer of a popular blog on archives and digital humanities, recently complained via two Twitter messages that non-archivists did not understand the way archivists work or think. "Nonarchivists think archivists=selection, deliberate creation of 'the archives'," she tweeted. "Which is somewhat accurate, but archivists strive not to 'create' archival collections. Our interactions should be minimized.” A few moments later, when another archivist countered with the argument that "Selecting 3-5\% of records...implies a huge contribution to the creation of the archive," Ms. Theimer agreed that appraisal was "critical intervention," but only on the

${ }^{131}$ Handlin, Truth in History, 276. 
Donnelly — Shaping the Future Past — 92

"Federal scale or [for] other large bureaucracies." So only in large bureaucracies is the intervention of the archivist in the creation of the collection "critical?" Otherwise, we are to assume that the archival hand being minimized also minimizes the fact that collections are a created thing?

As any historian knows, when doing research publication dates of articles and books must be checked. Authors must be looked up, because understanding something of the historian's own biases and how they have shaped their argument will enable better interpretations from this research. This should also apply to archives and, if possible, the archivists themselves. Why cannot more archivists do the same, where possible, rather than expecting the world that uses their sources to believe in the organic purity of their collections? Instead, acknowledge the hand of the archivist with an explanation of what has been done to shape the archive. It almost seems arrogant, looking from the outside in, for the archivist to stand there and insist that their intervention is "minimal.” They do not need to defend their position or their actions, but they need to explain them and be clear that there is an archival hand shaping these collections. Terry Cook insists that archivists "must allow ourselves to be held accountable by revealing the research-based and personal suppositions on which keep/destroy decisions have been made." There will be wrong decisions, he allows, and there will be mistakes, but, he finishes by stating, “...posterity needs to know why we left them the memory legacy that we did." ${ }^{132} \mathrm{c}$

132 Cook, "Remembering the Future: Appraisal of Records and the Role of Archives in Constructing Social Memory," 178. 
Donnelly — Shaping the Future Past — 93

The historian is required to make the case for why this one woman was important to history; the archivist has to trust that the historians and other seekers who access this information will bring their own skills and unique insight to the collection. It's not just about "leaving some up to the researcher;" it's understanding that too much direction hinders the possibilities of new insight and different information being drawn from this same material-and that would be a loss to all. But, then again, if archives are keepers of the past, they are also the records of what has been lost, "both imagined and real in societal memory." 133 Toward this end, then, information should be preserved and organized, but not owned to the point that the only person who understands the collection or any potential insight that might be generated is the one who generated it.

As Honor Sachs discovered in her research about Annie Christian, and like many today, Kwan Hsu had many masks. For Ms. Christian, her masks were so totally separated that her history became a single-faceted, almost caricature of the real woman. Often, for women, this has been our history, our truth in the past, missing and silenced from so many archives and collections as we are, our papers, the combined ephemera of even part of our lives deemed unimportant. But today, those gaps are being addressed, and with this collection, there is the chance to do more than just "address" that change; there is a chance to preserve records that fill a gap. The woman in this record is not a single-faceted person for all that the facsimile contained here cannot recreate her in her entirety. But her story can illuminate our past and inform our present in many ways. Kwan was a

133 Cox, No Innocent Deposits, 234. 
Donnelly — Shaping the Future Past — 94

woman who maybe did not accomplish all that she had hoped for, but who persevered, who never gave up, and who succeeded in many ways.

Hers is a history worth knowing and a story worth telling.

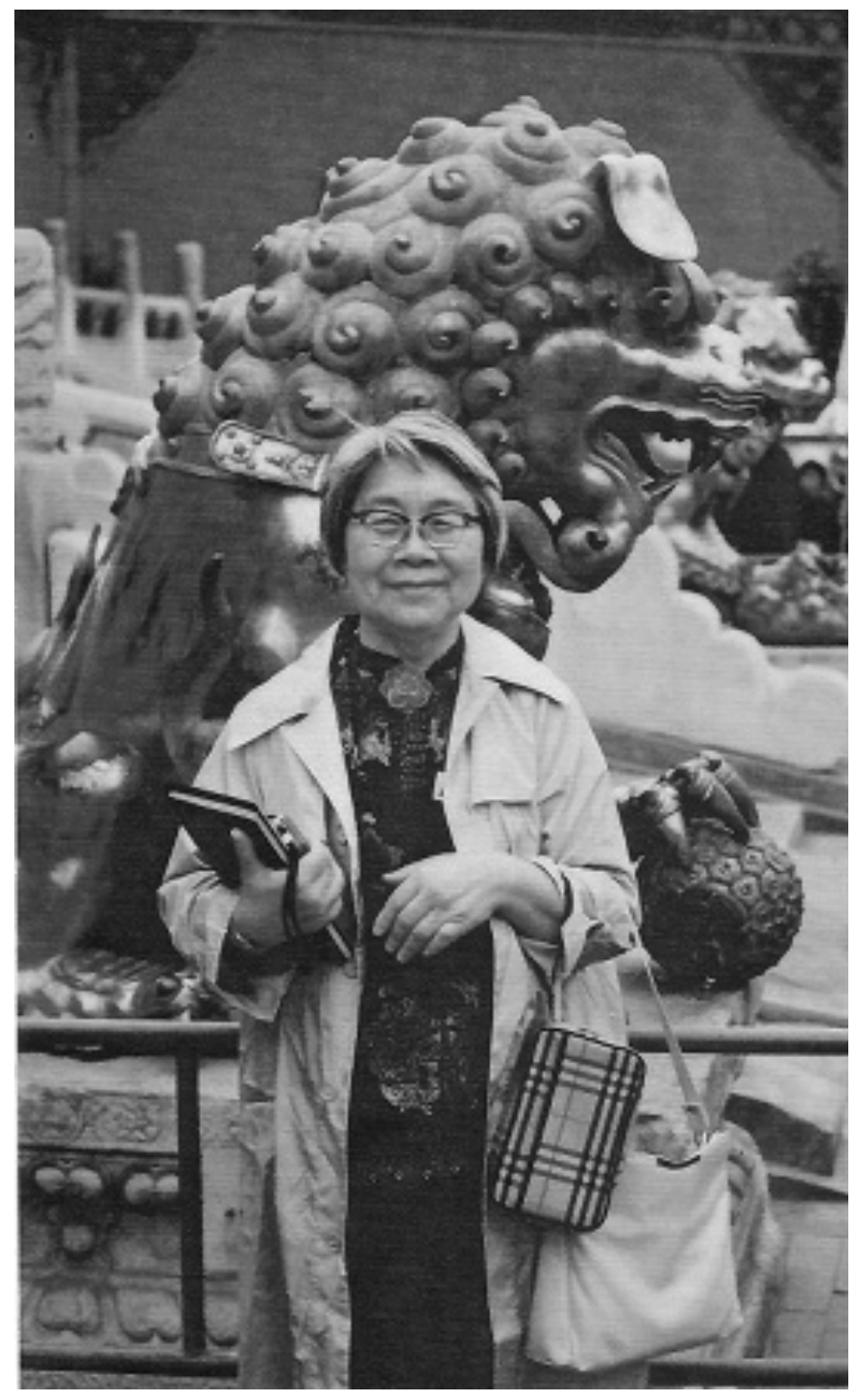

Figure 24 - Kwan Hsu in Beijing. 1986. (Image from the Kwan Hsu Papers, courtesy PSU Archive.) 
Donnelly — Shaping the Future Past — 95

\section{BIBLIOGRAPHY}

Appleby, Joyce, Lynne Hunt, and Margaret Jacob. Telling the Truth About History. New York: Norton, 1994.

Bailey, Paul. Gender and Education in China: Gender Discourses and Women's Schooling in the Early Twentieth Century. New York: Routledge, 2007.

Blouin, Francis X., and William G. Rosenberg. Processing the Past: Contesting Authorities in History and the Archives. 1st ed. Oxford University Press, USA, 2011.

Blouin, Francis, and William G. Rosenberg, eds. Archives, Documentation, and Institutions of Social Memory: Essays from the Sawyer Seminar. Ann Arbor: University of Michigan Press, 2006.

Burton, Robert. "The New Chinese in America." American University Field Staff Reports Service. East Asia Series (1966). 7, no. 8. East Asia Series (1966): 105116.

Cook, Terry. "Remembering the Future: Appraisal of Records and the Role of Archives in Constructing Social Memory." In Archives, Documentation, and Institutions of Social Memory: Essays from the Sawyer Seminar, edited by Francis Blouin, 169-181. Ann Arbor: University of Michigan Press, 2006.

- - - "The Archive(s) Is a Foreign Country: Historians, Archivists, and the Changing Archival Landscape." The Canadian Historical Review 90, no. 3 (September 16, 2009): 497-534.

Cox, Richard. No Innocent Deposits: Forming Archives by Rethinking Appraisal. Lanham Md.: Scarecrow Press, 2004.

Craig, Barbara L. "Setting the Students' Bearings and Balance in Appraisal." Archival Science 5, no. 2-4 (September 2006): 391-402.

Dillon, Nara. At the Crossroads of Empires: Middlemen, Social Networks, and StateBuilding in Republican Shanghai. Stanford, Calif.: Stanford University Press, 2008.

Evans, Richard. In Defense of History. [American ed.]. New York: W.W. Norton, 1999.

Gabaccia, Donna. "Is Everywhere Nowhere? Nomads, Nations, and the Immigrant Paradigm of United States History." The Journal of American History. 86, no. 3 (1999): 1115-1134. 
Donnelly — Shaping the Future Past — 96

Glosser, Susan. “'Women's Culture of Resistance' : an Ordinary Response to Extraordinary Circumstances." In In the Shadow of the Rising Sun: Shanghai Under Japanese Occupation, edited by Christian Henriot and Yeh, Wen-Hsin. Cambridge UK ;;New York: Cambridge University Press, 2004.

Handlin, Oscar. Truth in History. London ;;Cambridge Mass.: Belknap Press, 1979.

Henriot, Christian, and Yeh, Wen-Hsin. In the Shadow of the Rising Sun: Shanghai Under Japanese Occupation. Cambridge UK ; New York: Cambridge University Press, 2004.

Hipps, John. History of the University of Shanghai. [N.p.]: Board of Founders of the University of Shanghai, 1964.

Holcombe, Charles. The Genesis of East Asia, 221 B.C.-A.D. 907. Honolulu: Association for Asian Studies and University of Hawai'i Press, 2001.

Horne, Gerald. "Race from Power: U. S. Foreign Policy and the General Crisis of White Supremacy." In Window on Freedom: Race, Civil Rights, and Foreign Affairs, 1945-1988, edited by Brenda Plummer, 45-66. Chapel Hill: University of North Carolina Press, 2003.

Hsu, Kwan. "I Remember Papa", n.d.

- - - "Letter to C. K. Zhang", March 14, 1986. Kwan Hsu Papers. Portland State University Archives.

- _- "Letter to Mrs. Tobias and Eve", July 23, 1953. Portland State University Archives.

Huang, Nicole. "Fashioning Public Intellectuals : Women's Print Culture in Occupied Shanghai (1941-1945)." In In the Shadow of the Rising Sun: Shanghai Under Japanese Occupation, edited by Christian Henriot and Yeh. Cambridge UK ;;New York: Cambridge University Press, 2004.

Huang, Tchang Fong. "Letter to Carolyn Savage”, October 15, 1997. Kwan Hsu Papers, PSU.

Huang, Viola. “About China”, ca 1950. Kwan Hsu Papers, PSU.

Iowa State University Library. "Beatrice M. Bruner Dowd Papers, RS 21/7/117, Archives of Women in Science and Engineering, Special Collections Department", n.d. http://www.lib.iastate.edu/arch/rgrp/21-7-117.html.

———. "Guidelines for Discarding, Special Collections Department", n.d.

- - . "Guidelines for Donating to Special Collections", n.d. 
Donnelly — Shaping the Future Past — 97

- - - "Joan Stadler Papers, RS 13/25/59, Special Collections Department", n.d. http://www.lib.iastate.edu/arch/rgrp/13-25-59.html.

- - - "Kathleen M. Desmond Trahanovsky Papers, RS 13/6/58, Archives of Women in Science and Engineering, Special Collections Department", n.d. http://www.lib.iastate.edu/arch/rgrp/13-6-58.html.

——_. "Processing Manual, Special Collections Department", n.d.

Kammen, Michael. Mystic Chords of Memory: The Transformation of Tradition in American Culture. Random House Digital, Inc., 2011.

Koehn, Peter, and Xiao-huang Yin, eds. The Expanding Roles of Chinese Americans in U.S.-China Relations: Transnational Networks and Trans-Pacific Interactions. Armonk N.Y.: M.E. Sharpe, 2002.

Lago, Francesca Dal. “Crossed legs in 1930s Shanghai : how 'modern' the modern woman?" East Asian history, no. 19 (2000): 103-144.

Lai, Him. "I - Musings of a Chinese American Historian." Amerasia Journal. 26, no. 1 (2000): 2-31.

Lauren, Paul Gordon. "Seen from the Outside: The International Perspective on America's Dilemma." In Window on Freedom: Race, Civil Rights, and Foreign Affairs, 1945-1988, edited by Brenda Plummer, 21-43. Chapel Hill: University of North Carolina Press, 2003.

Lawrence, John. "Nuclear Medicine Pioneer and Director of Donner Laboratory, University of California, Berkeley: Oral History Transcript." Interview by Hughes, Sally Smith, 1980 1979. Internet Archive. http://www.archive.org/details/nuclearmedicine00lawrrich.

Lewis, Mark Edward. China Between Empires: The Northern and Southern Dynasties. Harvard University Press, 2009.

Lidofsky, Leon. “Chien-Shiung Wu, 29 May 1912. 16 February 1997.” Proceedings of the American Philosophical Society 145, no. 1 (2001): 116.

Linenthal, Edward. History Wars: the Enola Gay and Other Battles for the American Past. 1st ed. New York: Metropolitan Books, 1996.

Ling-Ling, Lien. "Leisure, Patriotism, and Identity: The Chinese Career Women's Club in Wartime Shanghai." In Creating Chinese Modernity: Knowledge and Everyday Life, 1900-1940, edited by Peter Zarrow. New York: Peter Lang, 2006. 
Donnelly — Shaping the Future Past — 98

Liu, Haiming. "Historical Connections Between the Chinese trans-Pacific Family and U.S.-China Relations." In The Expanding Roles of Chinese Americans in U.s.China Relations: Transnational Networks and Trans-Pacific Interactions, edited by Peter Koehn and Yin, Xiao-huang. Armonk N.Y.: M.E. Sharpe, 2002.

Lowenthal, David. "Archives, Heritage, and History." In Archives, Documentation, and Institutions of Social Memory: Essays from the Sawyer Seminar, edited by Francis Blouin, 193-206. Ann Arbor: University of Michigan Press, 2006.

Malcom, Shirley, Hall, Paula Quick, and Brown, Janet Welsh. "The Double Bind : the Price of Being a Minority Woman in Science : Report of a Conference of Minority Women Scientists, Airlie House, Warrenton, Virginia, December 1975". Washington D.C.: American Association for the Advancement of Science, 1976.

Mason, Karen. "Fostering Diversity in Archival Collections: The Iowa Women's Archives." Collection Management. 27, no. 2 (2002): 23.

Menne-Haritz, Angelika. "Appraisal or Documentation: Can We Appraise Archives by Selecting Content?" The American Archivist 57, no. 3 (1994): 528.

Nesmith, Tom. "What's History Got to Do With It?: Reconsidering the Place of Historical Knowledge in Archival Work." Archivaria., no. 57 (2004): 1-28.

Plummer, Brenda. Window on Freedom: Race, Civil Rights, and Foreign Affairs, 19451988. Chapel Hill: University of North Carolina Press, 2003.

Qian, Nanxiu. "Revitalizing the Xianyuan (Worthy Ladies) Tradition: Women in the 1898 Reforms." Modern China 29, no. 4 (October 1, 2003): 399-454.

Rainey, Lee. Confucius \& Confucianism the Essentials. Chichester, West Sussex, U.K. ;;Malden, MA :: Wiley-Blackwell,, 2010.

Rice, Tim. "The Lion King Lyrics - 'Circle of Life”, n.d. http://www.lionking.org/lyrics/OMPS/Circle-EJ.html.

Rosenzweig, Roy, and David Thelen. The Presence of the Past. Columbia University Press, 2000.

Rossiter, Margaret. Women Scientists in America: Before Affirmative Action, 19401972. Baltimore: Johns Hopkins University Press, 1995.

Sachs, Honor. "Reconstructing a Life: The Archival Challenges of Women's History." Library Trends 56, no. 3 (February 14, 2008): 650-666. 
Donnelly — Shaping the Future Past — 99

Savage, Carolyn. "Looking West Toward China: The Life and Letters of Hsu Kwan." Unpublished. Portland, OR, 1998. Portland State University Archive.

Schwartz, Joan. "Archives, Records, and Power: The Making of Modern Memory." Archival Science 2, no. 1-2 (January 1, 2002): 1-19.

Smith, Bonnie. The Gender of History Men, Women, and Historical Practice. Cambridge, Mass.: Harvard University Press,, 2000. http://hdl.handle.net/2027/heb.04359.0001.001.

Society of American Archivists., and Fredric Miller. Arranging and Describing Archives and Manuscripts. Chicago: Society of American Archivists, 1990.

Steedman, Carolyn. "'Something She Called a Fever' -- Michelet, Derrida, and Dust (Or, in the Archives with Michelet and Derrida.)." In Archives, Documentation, and Institutions of Social Memory: Essays from the Sawyer Seminar, edited by Francis Blouin, 4 - 19. Ann Arbor: University of Michigan Press, 2006.

Takaki, Ronald. Strangers from a Different Shore: a History of Asian Americans. Updated and rev. ed., 1. paperback ed. Boston [u.a.]: Little Brown, 1998.

Tan, Amy. "Amy Tan to Carolyn Savage", February 28, 1998. Kwan Hsu Papers. Portland State University Archive.

Voss-Hubbard, Anke. "No Document—No History': Mary Ritter Beard and the Early History of Women's Archives." The American Archivist 58, no. 1 (January 1, 1995): 16-30.

Wang, Zuoyue. "Chinese American Scientists and U.S.-China Scientific Relations: From Richard Nixon to Wen Ho Lee." In The Expanding Roles of Chinese Americans in U.s.-China Relations: Transnational Networks and Trans-Pacific Interactions, edited by Peter Koehn and Yin, Xiao-huang, 207-234. Armonk N.Y.: M.E. Sharpe, 2002.

- - - "Information on a Chinese-American Scientist - Klostes@gmail.com - Gmail", February 1, 2012.

https://mail.google.com/mail/u/0/?ui=2\&view=btop\&ver=18zqbez0n5t35\& q=wang\&qs=true \&search=query \&th=1353d0865e2dc788\&qt=wang. $1 \&$ cvid $=1$.

- - - "Transnational Science During the Cold War." Isis 101 (2010): 367-377.

-_- "Zuoyue Wang Homepage." Homepage. California State Polytechnic University, n.d. http://www.csupomona.edu/ zywang/. 
Westwick, Peter. '“Abraded from Several Corners:' Medical Physics and Biophysics at Berkeley." Historical Studies in the Physical and Biological Sciences: HSPS 27, no. 1 (1996): 131.

Wilson, Ian E. "The Real Thing for the Pepsi Generation." In Archives, Documentation, and Institutions of Social Memory: Essays from the Sawyer Seminar, edited by Francis Blouin and William G. Rosenberg, 333-342. Ann Arbor: University of Michigan Press, 2006.

Yeh, Wen-Hsin. "Huang Yanpei and the Chinese Society of Vocational Education in Shanghai Networking." In At the Crossroads of Empires: Middlemen, Social Networks, and State-building in Republican Shanghai, edited by Nara Dillon. Stanford, Calif.: Stanford University Press, 2008.

Yung, Judy. "Him Mark Lai: Reclaiming Chinese American History." The Public Historian 25, no. 1 (January 1, 2003): 51-69.

Zanish-Belcher, Tanya. "Documenting the Sometimes Invisible -- Working with Women Scientists." Humanities Collections 1, no. 4 (2001): 3.

Zarrow, Peter. Creating Chinese Modernity: Knowledge and Everyday Life, 1900-1940. New York: Peter Lang, 2006.

Zhu, Yuelin. "Chien-Shiung Wu: An Intellectual Biography”. Harvard University, 2001. 
Donnelly — Shaping the Future Past — 101

APPENDiX: Finding Aid For the Dr. KwAN Hsu PAPERS, CA. 1913 - 1995 PORTLAND

STATE UNIVERSITY ARCHIVES

N.D. - This finding aid is accurate for the time the thesis was submitted for graduation. A more current finding aid will be available after June, 2012, located at

http://archon.archives.pdx.edu.proxy.lib.pdx.edu/?p=collections/control card\&id $=127$

\begin{abstract}
:
The first Chinese woman to receive an American Association of University Women fellowship for advanced study abroad, Kwan Hsu arrived in the United States in 1947. Stranded here by the Maoist Revolution in 1949, Hsu eventually obtained both a Ph.D. in Physics and U.S. citizenship and was hired in 1964 to set up Portland State's first biophysics program.
\end{abstract}

\title{
Biography:
}

Born in Guăngxı̆ Province, China, in 1913, Kwan Hsu was raised in Batavia (Java) and Shanghai. Through her father's second wife, she was the niece of Huang Yanpei, founder of Chinese vocational education. Kwan graduated from the Baptist-run University of Shanghai in 1936 (B.Sc. in Physics), but her plans to go abroad for post-graduate education were derailed by the outbreak of the SinoJapanese war. Throughout the decade-long Japanese occupation of Shanghai, Kwan was the main breadwinner for her immediate family, supporting them by teaching physics at the University and also at three and four high schools at a time. After the war, the University of Shanghai and the Baptist Missionary Board, which oversaw its operations, arranged a scholarship for Kwan's postgraduate study in the United States. The American Association of University Women (AAUW) also awarded her a scholarship as part of their program to provide for the further education of women from war-ravaged countries. Kwan was the first Chinese woman to receive such a scholarship.

Enrolled at the University of Minnesota in the fall of 1947, Kwan obtained a Masters Degree in Physics in 1950. Though she matriculated into the State University of Iowa, she failed her first Ph.D. qualifying exams there. Having become interested in biophysics, Kwan shifted her focus from purely theoretical physics and began searching for a different school. In 1954, she was accepted at the University of California, Berkeley, and in 1960 received her Ph.D. in Biophysics. After graduation, she obtained a position as the assistant chief of biophysics at the Veterans Administration Hospital in Indianapolis, and as an assistant professor of Biophysics at Indiana University.

During Kwan's years as a student, she often traveled and spoke on behalf of the Baptist missionary board and the AAUW. She corresponded voluminously 
Donnelly — Shaping the Future Past - 102

with family and friends both in the United States and China. Stranded here by the Maoist revolution in 1949, when the United States withdrew all state personnel from the People's Republic of China (PRC) early in 1950, Kwan lost touch with all her family and friends back home. In 1963 Kwan suffered a seizure and was hospitalized in the Hinsdale Sanatorium in Indiana. She spent several of the next months as a patient there, receiving a total of 48 electroshock treatments (EST) to combat depression and "paranoia."

In 1964, with the help of her Ph.D. advisor at UC Berkeley, Dr. Cornelius Tobias, Kwan obtained a permanent position at then Portland State College (now PSU), becoming their first biophysics professor, charged with creating a subdepartment and drawing in students to the new courses. At Portland State Kwan taught, conducted and published her research, and spent a sabbatical year from 1970 - 71 researching in Sheffield, England. She received tenure and was heavily involved in the international studies program and in creating a China studies department at Portland State. Kwan retired in 1978, but remained an active researcher and participant in the Physics department until 1985.

Within the Portland community, Kwan was active both in her local church, the First Baptist Church of Portland, and in the U.S. China People's Friendship Association (USCPFA), an early group working to normalize relations between the PRC and the US. In 1972, through the auspices of the USCPFA, she obtained a Canadian visa and returned to Shanghai for the first time in twenty-five years. When Nixon reestablished ties with China, Kwan resumed contact with family, friends, and colleagues from her former university, now Shanghai Institute of Mechanical Engineering (SIME).

In the 1980 ond 1990 s, Kwan returned a number of times to China, leading tours for PSU students and professors, attending events the PRC held in honor of her Chinese family, working as a "consulting professor" at SIME, and visiting her own family. Active in the Huajiang University Alumni association, she was also the People's Republic of China's (PRC) cultural liaison with the Portland and Oregon business communities. She continued to work after her retirement, translating materials into Chinese for Portland area businesses and helping students from China gain visas and entrance into U.S. universities. Throughout her last years, she actively worked to promote cross-cultural understanding between the communities, and to connect academics in both countries with one another.

Dr. Kwan Hsŭ died in Portland in November of 1995.

\section{Scope and Content of Collection:}

The Kwan Hsu papers contain correspondence (both personal and professional), research, writings, diaries, immigration papers, curricula vitae, photos, and various publications that Kwan collected. Her writings include her Ph.D. thesis on the permeability of yeast cells and various other research publications, translations she made of materials for various businesses and private citizens, as well as personal autobiographical essays written after her retirement from 
teaching. Throughout her life, Hsu corresponded voluminously with friends and family and later kept copious diaries and notes about her daily activities. These personal papers make up the bulk of this collection.

Professionally, Kwan was active in the Radiation Research Society, the American Association of University Women (AAUW), and the Huijiang Alumni association, as well as numerous committees and councils at Portland State. Her community service ranged from serving on community advisory boards at a local television station, to her active membership in her church, the United States \& China People's Friendship Association, her ongoing work with the Baptist Foreign Missions, and various events as the cultural attache of the People's Republic of China.

\section{Separated Materials:}

Duplicate materials and widely available newspapers and publications have been weeded. Miscellaneous books and other materials were pulled as well, though lists were kept within the collection of the titles and other information. Medical records beyond diary entries and general research were also pulled. Where they were deemed helpful and appropriate, Carolyn Savage's notes and comments and other materials were placed within its own series.

\section{Processing Notes:}

$\mathrm{Xu} \mathrm{Ju}$, Kwan Hsu's brother, first gave the material in this collection to Kwan's long-time friend, Carolyn Savage. The native order was largely destroyed in the chronological assembly imposed by Ms. Savage as she worked on her manuscript about Dr. Hsu's life, and no attempt was made at reconstruction with the current ordering of the collection. Material that Ms. Savage had pulled out to use for her manuscript is still contained in separate folders, though those folders have been sorted into the appropriate series. The bulk of her research and comments, including her unpublished manuscript, "Looking West: The Life in Letters of Kwan Hsu," is contained in Series E, "Carolyn Savage and other papers." At this time, the collection has been minimally processed, materials having undergone general separation and ordering within relatively broad series. Carolyn Savage's material is being reintegrated into the rest of the collection.

\section{Current Series Listing:}

Series 1: Education

Series 2: Professional

Series 3: Personal

Series 4: Untranslated Chinese Materials \& other Ephemera

Series 5: Carolyn Savage papers

Series 1: Education, ca. 1923 - 1960, 1980 s 
This series contains records from Kwan's early years in China, pictures from her school years there, college transcripts, records of her search for a Ph.D. program, her dissertation, research notes, and so on. Papers and correspondence relating to her association with the AAUW are included here, as are her activities with the Huajiang Alumni Association (University of Shanghai) and the associated Baylor University Alumni group when diplomatic ties were reestablished with China.

\section{Box 1: Miscellaneous materials}

Materials selected by Carolyn Savage for her manuscript, 1923 1990 .

Photos from China, ca. 1923 - 1936.

Ph.D. thesis, 1960.

AAUW correspondence, all.

Baptist Mission Board correspondence

Iowa State University, 1950 - 1953.

Correspondence, Ph.D. program search, $1952-1954$

University of California, Berkeley (including Donner Laboratory), 1947, $1954-1960$

Scholarship correspondence, University of Shanghai, 1947

College Transcripts

\section{Box 2: University of Shanghai Alumni Material}

Correspondence, Baylor University, Huajiang Alumni Association, 1980 - 1990 s

Yearbooks, 1986, 1991

Alumni lists for Huijang University

Taiwan, US, Hong Kong, Beijing

History of the University of Shanghai, by John Burder Hipps

\section{Series 2: Professional, $1960-1995$}

This series includes materials relating to Kwan's work as a professor and her biophysics research. It also includes the few materials from her time teaching at the University of Shanghai in the 1930s and 1940s. Translation work is included here as well, since it was generally a paid contract basis. Material dealing with her time at Shanghai Institute of Mechanical Engineering (SIME) as a "Consulting Professor" in the mid-1980s will be found in the Education series, as that was heavily rooted in her work with the alumni association centered at Baylor University.

\section{Box 1, various}

Materials assembled by Carolyn Savage, 1960 - 1995. 
Student correspondence, University of Shanghai, 1947.

1960 - 1972:

Job search

V.A. Hospital

Civil service examination and investigation, 1960

Portland State College/University correspondence, research, etc.

Sabbatical at Sheffield University, England, 1971 - 1972, correspondence and photos

\section{Box 2: 1972 - 1989}

Radiation Research Society materials

Portland State University, Emeritus activities and correspondence Sheffield University, publications

Mah-Jongg rules

Translations: Ou Yang Shegeng Diary (Guide for Evans Fordyce

Carlson, 1938)

\section{Series 3: Personal ca. 1923 - 1995}

This series comprises the bulk of the collection, and consists largely of personal correspondence, notes and memos written and received by Kwan. Her diaries are here, as are medical records, computer disks, and papers concerning her community service work once she had settled in Portland, Oregon, in 1964. Kwan applied for and received Permanent Resident Alien status under the McCarrenWalters Act of 1953, and kept copies of the correspondence required throughout. The arrangement is roughly chronological at this time, though diaries and logs are not kept with the papers from the corresponding year at this time. Additionally, materials pulled by Carolyn Savage for her manuscript have not yet been reincorporated with their corresponding papers. "Papers" can include everything from correspondence dealing with her subscription to a book club to material dealing with diabetes, overseas travel, or community service work.

\section{Box 1 - Carolyn Savage organized materials (No specific dates)}

Correspondence with Chinese friends and family (Some in Chinese), various dates information on the Huang Yanpei family and other genealogical data

Programs and papers from the S.S. George Gordon, 1947

Immigration papers \& correspondence, 1953 - 1960

Community Service, 1980 s

Consolidated Chinese Benevolence Association

U.S. China People's Friendship Association treasurer's

report, etc. 
Photos from childhood in China

\section{Box 2 - Various papers, organized by Carolyn Savage}

Correspondence, mostly with friends in the United States

General papers - 1948 - 1962

Box 3 - Various Papers, 1963 - 1978

Photos

Papers

Correspondence

Box 4 - Various papers, 1985 - 1988

Papers

Trip to China with the International Foreign Mission, 1985

Correspondence, Travel plans

$\mathrm{X}$-rays (Shanghai)

Plaque (untranslated Chinese)

Box 5 - Various papers, 1990 - 1995

Inventories of computer disks contents, notes

Diabetes class, audiology, cataract report, 1991

Miscellaneous papers and correspondence, organized by C.S.

Box 6 - Papers \& logs, 1990 - 1995

Letter logs

Book logs

General papers \& correspondence

Calendars (Most with notes recording daily events/thoughts)

Box 7 - Photos \& Negatives, 1960s - 1970s

Box 8 - Various papers, 1979 - 1995

Diaries, $\quad 1979-1995$

Reading logs, $1979-1985$

Photos \& slides, 1984

Box 9 - Personal travel, 1979 - 1981

Photos \& Slides

Trip with CSEA 1979 (as translator)

Box 10 - Scrap books, photos and slides, various years 
Scrap books, including Tiananmen Square, 1989

Photos and slides, $1967-1969$

Box 11 - Computer disks, diaries and other logs (1962-1989)

Box of computer disks ( 5 1/4")

Diaries, $1962-1974$

Reading Logs 1970s-1980s

Expense logs, $1970 \mathrm{O} \& 1980 \mathrm{~s}$

\section{Series 4- Ephemera}

\section{Box 1 - Untranslated Chinese Correspondence}

(organized by Carolyn Savage)

\section{Series 5 - Carolyn Savage Papers}

\section{Box 1 - papers}

Manuscript, Looking West Towards China

Notes on people, events in Kwan Hsu's life

Correspondence (Including letters from Amy Tan, author. 